\title{
Kindlin-3 Mutation in Mesenchymal Stem Cells Results in Enhanced Chondrogenesis
}

Bethany A. Kerr ${ }^{1,2,3}$, Lihong $\mathrm{Shi}^{2}$, Alexander H. Jinnah ${ }^{3}$, Jeffrey S. Willey ${ }^{3,4}$, Donald P. Lennon ${ }^{5}$, Arnold I. Caplan ${ }^{5}$, Tatiana V. Byzova ${ }^{1}$

${ }^{1}$ Department of Molecular Cardiology, Joseph J. Jacobs Center for Thrombosis and Vascular Biology, Lerner Research Institute, Cleveland Clinic, Cleveland, Ohio, 44195

${ }^{2}$ Department of Cancer Biology and Comprehensive Cancer Center, Wake Forest School of Medicine, Winston-Salem, NC 27157

${ }^{3}$ Department of Orthopaedic Surgery, Wake Forest School of Medicine, Winston-Salem, NC 27157

${ }^{4}$ Department of Radiation Biology, Wake Forest School of Medicine, Winston-Salem, NC 27157

${ }^{5}$ Skeletal Research Center, Department of Biology, Case Western Reserve University, Cleveland, Ohio, 44106

Running Title: Kindlin-3 regulates chondrogenesis

Address correspondence to: Bethany Kerr, Ph.D., Wake Forest School of Medicine, 1 Medical Center Blvd, Winston-Salem, NC, 27157. Telephone: 336-716-0320; Twitter: @BethanyKerrLab; e-mail: bkerr@ wakehealth.edu; ORCID: 0000-0002-2995-7549

Number of Figures: 7

Number of Tables: 1 


\section{SUMMARY}

This study by Kerr et al. describes a new role for Kindlin-3 in controlling early chondrocyte differentiation from mesenchymal stem cells and later hypertrophic differentiation of chondrocytes.

\section{ABSTRACT}

Identifying patient mutations driving skeletal development disorders has driven our understanding of bone development. Integrin adhesion deficiency disease is caused by a Kindlin3 (fermitin family member 3) mutation and its inactivation results in bleeding disorders and osteopenia. In this study, we uncover a role for Kindlin-3 in the differentiation of bone marrow mesenchymal stem cells (BMSCs) down the chondrogenic lineage. Kindlin-3 expression increased with chondrogenic differentiation similar to RUNX2. BMSCs isolated from a Kindlin3 deficient patient expressed chondrocyte markers including SOX9 under basal conditions, which were further enhanced with chondrogenic differentiation. Rescue of integrin activation by a constitutively activated $\beta_{3}$ integrin construct increased adhesion to multiple extracellular matrices and reduced SOX9 expression to basal levels. Growth plates from mice expressing a mutated Kindlin-3 with the integrin binding site ablated demonstrated alterations in chondrocyte maturation similar to that seen with the human Kindlin-3 deficient BMSCs. These findings suggest that Kindlin-3 expression mirrors RUNX2 during chondrogenesis.

The abbreviations used are: 3D: three dimensional, BMSC: Bone marrow-derived mesenchymal stem cell, BSA: Bovine serum albumin, DMEM-LG: Dulbecco's Modified Eagle's MediumLow Glucose, IADD: integrin adhesions deficiency disease, K3KI: Kindlin-3 knock-in, LAD: 
leukocyte adhesion deficiency, MSC: mesenchymal stem cell, TGF: transforming growth factor, TRAP: tartrate-resistant acid phosphatase

Keywords: Kindlin-3/FERMT3, chondrogenesis, mesenchymal stem cell, RUNX2/Cbfa-1, bone development 


\section{INTRODUCTION}

Although our understanding of skeletal development in vertebrates has substantially improved through the use of animal models (Long and Ornitz, 2013), our progress in unraveling human bone development remains limited. Moreover, discrepancies between the effects of inhibitors and genetic ablations in mice (Long and Ornitz, 2013) complicate animal model-based analyses of key pathways underlying endochondral ossification, the main process of skeletal long-bone development. This knowledge is essential not only for understanding development and aging, but also for skeletal disease treatment, orthopaedic injury repair, and bone regenerative medicine. While a number of growth factors and their receptors ranging from FGFs to WNTs as well as transcriptional regulators such as SOX9 and RUNX2 are implicated in bone development, it remains unclear how these signals are integrated within specific bone microenvironments.

Loss-of-function mutations in patients with skeletal development complications represent a unique opportunity to uncover the function of specific proteins in human bone formation. Integrin activation deficiency disease (IADD, also called LAD-III), a rare immunodeficiency, presents in patients as severe bleeding, frequent infections, and osteopetrosis, and is caused by Kindlin-3 (fermitin family member 3) deficiency (Malinin et al., 2009). Kindlins (fermitin family members) function as intracellular adaptors or scaffold proteins involved in inside-out integrin activation by direct binding to the tail of the integrin $\beta$ subunit (Plow et al., 2009; Moser et al., 2008). A role for Kindlin-2 in chondrogenesis was recently uncovered (Wu et al., 2015). Deletion of Kindlin-2 in mesenchymal stem cells (MSCs) resulted in reduced chondrocyte proliferation and columnar organization. The skeletal defects generated by Kindlin-2 loss 
indicated a potential role in both intramembranous and endochondral ossification. Further, development of the primary ossification center was impaired leading to limb shortening in mice.

Unlike the ubiquitously expressed Kindlin-2, Kindlin-3 is detected primarily in hematopoietic and endothelial cells. Therefore, the origin of malignant infantile osteopetrosis, i.e., high bone density in Kindlin-3 deficient patients, was traced to impaired bone resorption by osteoclasts originating from the myeloid lineage in bone marrow (Crazzolara et al., 2015; Malinin et al., 2009; Sabnis et al., 2010). However, there is evidence that this osteoclast dysfunction and osteopetrosis is associated with MSC defects (Uckan et al., 2009). The severity of bone problems in Kindlin 3 deficient patients suggests functional defects in other cell types critically involved in bone development and possibly operating in close contact with the hematopoietic stem cell niche. While bone resorption is performed by osteoclasts, differentiation and maturation of MSCs underlie chondrogenesis and ossification. However, there are no reports suggesting either presence or a function of Kindlin-3 in MSCs and bone formation.

In order to understand the mechanisms of bone development in humans we took advantage of bone marrow samples from a previously described Kindlin-3 deficient IADD patients (Malinin et al., 2009) and examined changes in bone marrow-derived mesenchymal stem cells (BMSC) proliferation and adhesion, as well as chondrogenic differentiation. To mechanistically implicate Kindlin-3 as an integrin adaptor, we utilized knock-in mice expressing a Kindlin-3 mutant that is deficient in integrin binding. Utilizing these two models, we demonstrate that Kindlin-3 regulates chondrocyte differentiation and maturation. 


\section{METHODS}

\section{Clinical Samples}

Studies were conducted in accordance with the ethical standards of the Institutional Review Board at University Hospitals of Cleveland and with the Helsinki Declaration of 1975, as revised in 2000. Informed consent was obtained from all individuals. Details of the subject's histories were previously described (Malinin et al., 2009).

\section{Reagents}

All chemicals were obtained from Sigma unless otherwise specified. Media and cell culture reagents were supplied by the Central Cell Services Core of the Lerner Research Institute.

\section{Bone Marrow Culture}

Samples of patient bone marrow before bone marrow transplant were collected (subject). Separately, bone marrow was collected from a normal volunteer (control). Samples were rinsed with Dulbecco's Modified Eagle's Medium- low glucose (DMEM-LG) supplemented with 10\% FBS (growth media) from a lot selected for expansion and differentiation of human bone marrow-derived mesenchymal stem cells (BMSCs). The marrow cells were then centrifuged on a Percoll gradient as described previously (Solchaga et al., 2004; Lennon and Caplan, 2006). Cells from the top $10 \mathrm{~mL}$ of the gradient were collected and seeded into $100 \mathrm{~mm}$ tissue culture dishes at a density of $10 \times 10^{6}$ cells per dish; additional dishes were seeded at densities of 5 and $1 \times 10^{6}$ cells for determination of the number of colonies. Cells were cultured until passage four at which point they were plated at 3000 cells per $\mathrm{cm}^{2}$ for the following studies. Differentiation of BMSCs 
along the chondrogenic pathways in vitro was completed as described elsewhere (Solchaga et al., 2004; Lennon et al., 1995; Dennis et al., 1998). For chondrogenesis, DMEM-LG was supplemented with $0.1 \mu \mathrm{M}$ dexamethasone, $1 \%$ ITS+Premix, $50 \mu \mathrm{M}$ ascorbic acid 2-phosphate (Wako), and $1 \mathrm{mM}$ sodium pyruvate (control media). Control medium was then augmented with $10 \mathrm{ng} / \mathrm{mL}$ recombinant human TGF- $\beta 1$ (R\&D Systems; chondrogenic media) to induce chondrogenesis. For pellet cultures, BMSCs were placed in $15 \mathrm{~mL}$ conical tubes $\left(3 \times 10^{5}\right.$ cells/tube) and centrifuged at $2000 \mathrm{rpm}$. Cell pellet media was changed to control or chondrogenic after 24 hours.

\section{Immunofluorescence}

Cultures were plated on $10 \mu \mathrm{g} / \mathrm{mL}$ collagen type I coated coverslips in 24 well plates. Cultures were maintained in growth, control, or chondrogenic media, and fixed at 7 days. Fixed cultures were permeabilized by incubation with $0.2 \%$ Triton-X100. Cultures were stained with primary rabbit anti-KINDLIN-3 antibody (described previously (Bialkowska et al., 2010)). Cells were then stained with an anti-rabbit Alexa Fluor 488 conjugated secondary antibody (Molecular Probes; RRID: AB_143165) and phalloidin-Alexa Fluor 568 probe (Molecular Probes). Coverslips were mounted onto slides with Vectashield+DAPI (Vector Laboratories; RRID: AB_2336790). Photographs were taken with either a TCS-SPE (Leica; RRID: SCR_002140) or ZMZ1000 (Nikon) microscope with a 20x objective. The mean fluorescence intensity of individual channels was measured using NIH ImageJ (RRID: SCR_003070).

\section{RNA Isolation and $q P C R$}

RNA was isolated from BMSCs using the Qiagen RNeasy Mini Kit and cDNAs were prepared using the Clontech Advantage RT-for-PCR kit followed by real-time qPCR using the 
BioRad iQ SYBR green Supermix and measured on a Bio-Rad myIQ2 iCycler. Primers are shown in Table 1. The Kindlin primers were previously described (Bialkowska et al., 2010). Data were analyzed by the $\Delta \Delta \mathrm{C}_{\mathrm{T}}$ method.

\section{Immunoblotting}

Control BMSCs were lysed by incubation with RIPA buffer (Pierce) and $1 \mathrm{mM}$ protease inhibitors (Complete Mini, Roche). Samples were incubated with 5X Lane Marker Reducing sample buffer (Pierce) and boiled at $95^{\circ} \mathrm{C}$ for $10 \mathrm{~min}$. Samples underwent electrophoresis on an $8 \%$ polyacrylamide gel at $100 \mathrm{~V}$ for approximately 2 hours. Proteins were transferred to a nitrocellulose membrane at $100 \mathrm{~V}$ for 1 hour at $4^{\circ} \mathrm{C}$. Membranes were blocked in $5 \%$ BSA in TBS containing $0.1 \%$ Tween-20. KINDLIN-3 antibody (described previously (Bialkowska et al., 2010)) followed by an IRDye 800CW-conjugated anti-rabbit secondary antibody (LI-COR Biosciences; RRID: AB_621848) was used to visualize proteins. Membranes were scanned with the Odyssey LI-COR infrared scanner in the Lerner Research Institute Imaging Core with excitation at $778 \mathrm{~nm}$ and emission at $795 \mathrm{~nm}$.

\section{Flow Cytometry}

Cultures were maintained in growth, control, or chondrogenic media. Cultures were trypsinized at 6, 12, or 23 days, washed, and prepared for flow cytometry. In brief, cells were incubated with human Fc fragment for 15 minutes to block non-specific binding. Cells were stained with directly conjugated antibodies against human proteins: alkaline phosphatase-APC (R\&D Systems; RRID: AB_357039), CD73-PE (BD Biosciences; RRID: AB_2033967), CD45FITC (BD Biosciences; RRID: AB_2732010), CXCR4-PE (R\&D Systems), CD146-PE (R\&D Systems), CD29-PE (BioLegend; RRID: AB_314320), CD90-FITC (BioLegend; RRID: 
AB_893429), CD105-FITC (BioLegend; RRID: AB_755956), CD44-FITC (BioLegend; RRID:AB_312957)， CD117-PE/Cy7 (BioLegend; RRID: AB_893228)， CD11b-PE (eBiosciences; RRID: AB_2043799), CD34-FITC (BioLegend; RRID: AB_1731852), CD133APC (Miltenyi Biotech). After staining, cells were washed twice in 1X PBS and resuspended in $1 \%$ formalin. For intracellular staining, samples were fixed for 10 minutes in $10 \%$ formalin. Cells were then stained with anti-human osteocalcin-PE (R\&D Systems) in SAP buffer (HBSS with $0.1 \%$ saponin and $0.05 \%$ sodium azide). Cells were then washed twice with SAP buffer and resuspended in PBS. The stained cells were then analyzed using a BD FACS Canto II running the FACS Diva software. Fluorescence values of stained cells were normalized to a corresponding isotype-fluorochrome labeled control sample.

\section{Adhesion Assay}

Wells of 96 well plates were coated with $1 \%$ gelatin, $10 \mu \mathrm{g} / \mathrm{mL}$ collagen type I, $10 \mu \mathrm{g} / \mathrm{mL}$ collagen type II (BD Biosciences), $10 \mu \mathrm{g} / \mathrm{mL}$ fibronectin (BD Biosciences), $10 \mu \mathrm{g} / \mathrm{mL}$ fibrinogen (gift from Dr. Edward Plow), $10 \mu \mathrm{g} / \mathrm{mL}$ vitronectin (R\&D Systems), $10 \mu \mathrm{g} / \mathrm{mL}$ laminin (BD Biosciences), $1 \mathrm{mg} / \mathrm{mL}$ fibronectin or $1 \mathrm{mg} / \mathrm{mL}$ fibrinogen at $37^{\circ} \mathrm{C}$ overnight and then blocked with $0.1 \%$ BSA for 1 hour prior to plating. We used BSA coated wells as a control for weak substrate attachment. Before plating cells were incubated in a calcein-AM green solution (Invitrogen) for 30 minutes at $37^{\circ} \mathrm{C}$. Cells were allowed to attach for one hour. Calcein fluorescence was read at $485 \mathrm{~nm}$ excitation and $538 \mathrm{~nm}$ emission (SpectraMAX Gemini XS, Molecular Devices). Values were normalized to the BSA control.

\section{Proliferation Assay}


Cells were plated in growth media at a density of 2500 cells/well on either tissue culture plastic or plates coated with $10 \mu \mathrm{g} / \mathrm{mL}$ collagen type I, $10 \mu \mathrm{g} / \mathrm{mL}$ collagen type II, $10 \mu \mathrm{g} / \mathrm{mL}$ fibronectin or $10 \mu \mathrm{g} / \mathrm{mL}$ vitronectin. The CyQUANT NF Cell Proliferation Assay Kit (Molecular Probes) was used to quantify cell numbers after 4 hours, 1, 3, and 5 days. The assay was performed according to the manufacturer's protocol, and fluorescence was read at $485 \mathrm{~nm}$ excitation and $538 \mathrm{~nm}$ emission (SpectraMAX Gemini XS, Molecular Devices).

\section{Histochemical Staining}

Matrix produced by cells was assessed histochemically as described previously (Kerr et al., 2008). In brief, sulfated proteoglycans were fixed in $10 \%$ formalin and stained for 30 minutes with 1\% Alcian Blue 8GS solution (Electron Microscopy Sciences) on day 12 after plating. Alcian Blue staining was quantified by incubation of $4 \mathrm{M}$ guanidine $\mathrm{HCl}$ for $15 \mathrm{~min}$. The absorbance of the solution was read at 590nm with a visible plate reader (Vmax, Molecular Devices). Alkaline phosphatase production was assessed histochemically. Cells were incubated with a staining solution of $0.5 \mathrm{mg} / \mathrm{mL}$ Naphthol AS-MX phosphate and $1 \mathrm{mg} / \mathrm{mL}$ Fast Red in 50 $\mathrm{mM}$ Tris- $\mathrm{HCl}(\mathrm{pH} 9.0)$ for $15 \mathrm{~min}$ at $37^{\circ} \mathrm{C}$ and then fixed with $10 \%$ formalin on day 12 after plating. Histochemical staining was quantified by densitometry using NIH ImageJ.

\section{Biochemical Assays}

For alkaline phosphatase activity and DNA content analysis, cultures were lysed in $0.2 \%$ Triton X-100 on day 12 after plating. Lysates were incubated with $0.5 \mathrm{mM} \mathrm{MgCl}, 0.5 \mathrm{mM}$ paranitrophenol phosphate, and $0.5 \mathrm{M}$ Tris- $\mathrm{HCl}(\mathrm{pH} 9.0)$ for $30 \mathrm{~min}$ at $37^{\circ} \mathrm{C}$. The reaction was stopped with $1 \mathrm{~N} \mathrm{NaOH}$, and the absorbance was read at $410 \mathrm{~nm}$ with a visible plate reader (Vmax, Molecular Devices). A standard curve of alkaline phosphatase activity was created with 
dilutions of the 4-nitrophenol solution. To normalize samples, DNA content was measured. Lysates were incubated with $0.02 \mathrm{~N} \mathrm{NaOH}$ and $0.1 \mathrm{~g} / \mathrm{mL}$ diaminobenzoic acid for $45 \mathrm{~min}$ at $65^{\circ} \mathrm{C}$. The reaction was stopped with $2 \mathrm{~N} \mathrm{HCl}$, and the fluorescence was read at and emission of $420 \mathrm{~nm}$ and analysis of $510 \mathrm{~nm}$ (SpectraMAX Gemini XS, Molecular Devices). A standard curve was created with calf thymus DNA. Both plate readers use the SOFTmax PRO 4.0 software (Molecular Devices; RRID: SCR_014240).

\section{Transfection}

Subject BMSC's were plated in 6 well plates $\left(2 \times 10^{5}\right.$ cells/well) and incubated with $4 \mu \mathrm{g}$ of WT $\beta_{3}$ integrin or DR $\beta_{3}$ integrin DNA per well in the presence of Lipofectamine2000 (McCabe et al., 2007) resulting in a greater than 90\% transfection efficiency. After 3 hours, media was changed to control or chondrogenic. After 3 days, cells were lysed for RNA isolation and qPCR as described above.

\section{Animal Studies}

K3KI knock-in mice were generated as previously described (Xu et al., 2014; Meller et al., 2017). Bones were collected from male and female K3KI mice and wild-type (WT) littermates at 9 weeks of age under a Cleveland Clinic IACUC approved animal protocol ( $n=14$ 17). Bones were fixed in $10 \%$ formalin, decalcified in $14 \%$ neutral EDTA, and embedded in paraffin. Sections were stained with hematoxylin and eosin $(\mathrm{H} \& \mathrm{E})$, Toluidine blue, or Safranin O and Fast Green. TRAP (tartrate-resistant acid phosphatase) staining was completed as previously described (McCabe et al., 2011). Immunohistochemistry of bone sections was performed using antibodies against SOX9 (Abcam; RRID: AB_2728660), collagen type X (Abcam; RRID: AB_879742), and collagen type II (Abcam; RRID: AB_731688) after antigen retrieval and 
hydrogen peroxide treatment. Staining was visualized with DAB. Slides were scanned using a Hamamatsu NanoZoomer by the Virtual Microscopy Core in the Wake Forest School of Medicine. Bone histomorphometry, osteoclast numbers, and growth plate organization were analyzed with the BioQuant Osteo software (RRID: SCR_016423). Immunostaining was quantified using the VisioPharm digital pathology analysis software. Briefly, a region of interest was drawn around the growth plate, and the total cell number within the region counted. We then used custom-designed apps to count the number of positively stained cells within the region.

\section{Statistical Analysis}

Student's $t$ test analysis or one-way ANOVA analysis with Tukey post-test were used to determine statistical significance using GraphPad Prism 7.0 software (RRID: SCR_002798). * represents $\mathrm{p}<0.05, * *$ represents $\mathrm{p}<0.01, * * *$ represents $\mathrm{p}<0.005$. 


\section{RESULTS}

Kindlin-3 is expressed in BMSCs

We identified a point mutation in the Kindlin-3 FERMT3 gene ablating integrin activation in humans. These patients presented with severe bleeding, frequent infections, and osteopetrosis localized to the proximal area of the growth plate. Bone marrow transplantation resolved the clinical problems (Malinin et al., 2009). Bone marrow-derived mesenchymal stem cells (BMSCs) were isolated from the subject before bone marrow transplantation. To characterize the BMSCs, we assessed established mesenchymal stem cell and hematopoietic stem cell surface markers by flow cytometry (Dominici et al., 2006). Normal and subject BMSC expressed markers of mesenchymal cells: CD90, CXCR4, CD73, CD105, CD146, CD44, and CD29 (Figure S1). Correspondingly, no makers for hematopoietic stem cells were expressed (Figure S1). These verified BMSCs were used in subsequent experiments comparing normal and Kindlin-3 deficient BMSCs.

Kindlin-3 expression was previously demonstrated in cartilage (Ussar et al., 2006), however, its presence in BMSCs remained to be determined. By immunoblotting, normal BMSCs demonstrated Kindlin-3 protein levels equivalent to human umbilical vein endothelial cells (Figure S2A), which were previously shown to express low levels of Kindlin-3 (Bialkowska et al., 2010). To assess how integrin activation might alter Kindlin-3 expression, cells were plated on tissue culture plastic (control), fibronectin, collagen type I, or collagen type II coated dishes. Gene expression of Kindlin-3/FERMT3 was not altered with culture on different substrates (Figure S2B). To examine how 3D, micromass culture and cell-cell contact might alter Kindlin gene expression, normal BMCS were cultured in a monolayer or in pellets. Kindlin- 
3/FERMT3 gene expression was increased by $\sim 32$-fold when cells were grown in 3D pellet cultures (Figure S2C). Conversely, levels of Kindlin-2/FERMT2 expression were not changed. Thus, Kindlin-3 is expressed in normal BMSCs, and this expression is enhanced under more physiologic, 3D conditions.

Kindlin-3 is induced during chondrogenesis

As the 3D pellet is representative of the mesenchymal condensation during chondrogenesis (Solursh et al., 1982), we closely examined Kindlin-3 expression in normal BMSCs on gelatin-coated coverslips after chondrogenic induction. Stimulation of chondrogenesis induced cytoplasmic Kindlin-3 protein expression 9.6-fold in cultured BMSCs (Figure 1A). In addition, actin filament formation was increased 6.5-fold in cells treated with chondrogenic media compared with BMSCs cultured in control media (Figure 1A). Consistent with protein expression, gene expression of Kindlin-3/FERMT3 increased with time in chondrogenic media, showing its highest expression at day 14 when it was 5.3-fold higher than BMSCs cultured in control media (Figure 1B). Thus, Kindlin-3 expression mirrored the increase over time of the terminal chondrogenic marker $R U N X 2$ (runt-related transcription factor 2) expression (Figure 1C) (Chen et al., 2014; Inada et al., 1999). Thus, Kindlin-3 expression parallels RUNX2 expression during chondrogenesis in BMSC.

To ascertain Kindlin-3's role in chondrocyte maturation, 9-week old WT murine growth plates were stained for Kindlin-3 and markers of chondrocyte differentiation (Figure 1D). Collagen type II and SOX9 were localized to proliferative and columnar chondrocytes, while collagen type $\mathrm{X}$ was found predominately in hypertrophic chondrocytes (Figure 1D). Kindlin-3 was highly expressed in bone marrow cells in accordance with prior studies demonstrating its 
presence in hematopoietic stem cells and immune cells. In the growth plate, Kindlin-3 staining was found in both early and hypertrophic chondrocytes (Figure1D), indicating that Kindlin-3 may function at two distinct points during chondrogenesis.

\section{Kindlin-3 deficiency alters BMSC adhesion, proliferation, and differentiation}

In our initial characterization of the Kindlin-3 deficient patient, we demonstrated that a loss of Kindlin-3 diminished lymphocyte adhesion by disabling integrin activation (Malinin et al., 2009). Comparing the adhesion of normal and subject BMSCs to collagen type I, collagen type II, fibronectin, and vitronectin, we confirm that the Kindlin-3 deficient BMSCs displayed decreased attachment (Figure 2A) likely due to the lack of integrin activation. Interestingly, these BMSCs proliferated faster on all substrates tested (Figure 2B-F) demonstrating that the diminished adhesion permits a higher rate of proliferation. This is in line with prior studies demonstrating that focal adhesions dissolve and attachment to the extracellular matrix is reduced during cell division (Jones et al., 2018; Fang et al., 1996; Matus et al., 2014).

Our previous study demonstrated that the subject's BMSCs stimulated increased differentiation of bone and cartilage compared to control and subject post BMT cells when loaded into ceramic cubes and injected into immunocompromised mice (Malinin et al., 2009). To determine how Kindlin-3 deficiency alters BMSC differentiation, we analyzed normal and subject cells in a variety of chondrogenic assays. First, cells were plated on collagen type I and grown in control media or chondrogenic media containing TGF- $\beta 1$ and proteoglycan accumulation was measured as a marker for chondrocyte differentiation. Alcian blue staining to visualize proteoglycan deposition and densitometric analysis demonstrated increased proteoglycan release by the subject cells even in control media, while in chondrogenic media, 
proteoglycan release was further enhanced 2.5-fold in subject Kindlin-3 deficient cells (Figure 3A) Chondrogenesis is also marked by a decrease in alkaline phosphatase production. First, alkaline phosphatase expression was examined histochemically. In control media, subject cells displayed 2-fold decreased alkaline phosphatase expression compared with normal BMSCs (Figure 3B). Second, alkaline phosphatase activity was measured biochemically, and a 5.8-fold decrease was found in the subject BMSCs compared with normal cells in control media (Figure 3C).

Finally, SOX9 expression was examined as a marker of chondrogenic initiation. SOX9 (Sex Determining Region Y-Box 9) is required for chondrogenesis, and its expression inhibits the transition into hypertrophy and terminal differentiation by decreasing RUNX2 expression (Dy et al., 2012). The expression of SOX9 was 4.6-fold higher in subject Kindlin-3 deficient BMSCs in control media compared with normal cells. SOX9 expression was upregulated by chondrogenic media (TGF- $\beta 1$ treatment) as expected, although subject cells had 10.8-fold higher expression compared with normal BMSCs (Figure 3D). These data indicate that even prior to chondrogenesis initiation the Kindlin-3 null BMSCs are already advanced along the chondrogenic differentiation pathway.

To confirm that the differentiation of BMSCs from the Kindlin-3 deficient subject was more advanced, we examined the expression of a variety of chondrogenesis-related genes in BMSCs cultured in control media (Figure 4). Most of the genes associated with chondrocyte maturation (Majumdar et al., 2003) were upregulated in BMSCs isolated from the Kindlin-3 deficient subject with the exception of $R U N X 2$ expression which was significantly lower in the subject BMSCs (Figure 4) and is required for endochondral ossification and late chondrocyte maturation (Chen et al., 2014; Inada et al., 1999). Genes upregulated in the subject's BMSC in 
the absence of differentiation media included matrix metalloproteinases required for chondrocyte hypertrophy: MMP7 (3.6-fold) and MMP13 (5.8-fold) (Mackie et al., 2008), and extracellular matrix proteins associated with chondrocyte maturation: collagens (COL2A1, 115.8-fold and COL10A1, 311.8-fold) (Häusler et al., 2002), aggrecan (ACAN, 73.7-fold), and bone sialoprotein/Spp1/osteopontin (IBSP, 41.9-fold). Additionally, transcription and growth factorrelated genes driving early chondrocyte differentiation were higher in subject BMSCs: Osterix/Sp7 (OSX, 14.7-fold), SOX9 (SOX9, 8.4-fold), BAPX1/NKX3-2 (BAPX1, 981.5-fold), bone morphogenic protein 2 (BMP2, 191.5-fold), parathyroid hormone-related protein (PTHRP, 1685.1-fold), and fibroblast growth factor receptor 3 (FGFR3, 140.2-fold). Thus, the genes associated with early chondrocyte differentiation and SOX9 expression were upregulated in Kindlin-3 deficient BMSCs without any stimulation, while RUNX2 expression was decreased which could prevent terminal differentiation.

Kindlin-3 deficiency is rescued by constitutive integrin activation

To evaluate whether expression of constitutively active integrin could bypass the requirement for Kindlin-3 and thereby rescue abnormalities caused by Kindlin-3 deficiency, subject BMSCs were transfected with either WT $\beta_{3}$ integrin or a constitutively active DR $\beta_{3}$ integrin mutant (McCabe et al., 2007). As anticipated, active integrin expression enhanced subject BMSC adhesion 3-fold on collagen type I, collagen type II, and fibronectin substrates demonstrating that expression of active but not WT integrin bypasses the requirement for Kindlin-3 for integrin-mediated adhesion (Figure 5A). Expression of active but not WT integrin was able to revert subject BMSCs to an earlier stage in chondrogenic differentiation as demonstrated by diminished SOX9 expression in cultures treated with chondrogenic media 
(Figure 5B). Thus, expression of activated $\beta_{3}$ integrin overcomes the Kindlin-3 deficiency rescuing cell adhesion and the associated differentiation.

\section{Mutated Kindlin-3 mice display disrupted growth plate chondrogenesis}

To confirm the functional role of Kindlin-3 integrin axis in chondrogenesis, we examined the growth plates of Kindlin-3 mutant mice. The K3KI mutated Kindlin-3 knock-in mice contain a double mutation $\left(\mathrm{Q}^{597} \mathrm{~W}^{598} / \mathrm{AA}\right)$ designed to disrupt the integrin recognition region resulting in diminished integrin binding (Xu et al., 2014, 2015). Integrin expression in these mice remains equal to WT mice (Meller et al., 2017). Growth plates in 9-week old K3KI and WT mice were stained for markers of cartilage maturation. The overall structure of the growth plate was examined via Movat's pentachrome staining, while Safranin O and Fast Green were used to differentiate the growth plate area (Figure 6A). The trabecular bone volume appears higher in K3KI mice, while growth plates between WT and K3KI mice are approximately the same size. Mutation of Kindlin-3 resulted in the continued presence of hypertrophic cells in the ossification front of K3KI bones, while hypertrophic chondrocytes underwent terminal differentiation and were lost in the WT bones (Figure 6A). The expression and localization of the chondrocyte differentiation markers SOX9, collagen type II, and collagen type $\mathrm{X}$ were visualized by immunohistochemistry (Figure 6B). All three makers demonstrated 1.2-fold higher staining in the K3KI growth plates compared with WT growth plates confirming that the integrin-binding function of Kindlin-3 drives the changes in chondrogenic maturation markers seen in BMSCs. Additionally, bone histomorphometry of H\&E and TRAP stained bones demonstrated 2.3-fold increased bone formation (BV/TV) with an associated 1.3-fold decrease in trabecular spacing but no change in trabecular number (Figure S3A-C). These data are in accordance with the osteopetrosis seen in Kindlin-3 deficient patients (Yarali et al., 2003; Malinin et al., 2009). 
Further, TRAP staining demonstrated increased numbers of osteoclasts in K3KI mice (Figure S3D-E) similar to Kindlin-3 deficient mice (Schmidt et al., 2011). These changes in the growth plate structure indicate a second potential mechanism for the osteopetrosis in Kindlin-3 deficient, IADD patients. 


\section{DISCUSSION}

In this study, we demonstrate that Kindlin-3 regulates chondrogenesis in MSCs. Temporal Kindlin-3 expression was associated with BMSC differentiation towards the chondrocyte lineage and with increased chondrocyte maturation. As with cells of the hematopoietic lineage, Kindlin-3 loss diminished BMSC adhesion to a variety of substrates resulting in increased proliferation. Under basal conditions, BMSCs lacking Kindlin-3 expressed chondrocyte markers which were further upregulated upon chondrogenic induction. Constitutive integrin activation in Kindlin-3 deficient BMSCs rescued cell adhesion and reduced SOX9 expression. Growth plates in mice with Kindlin-3 integrin binding blocked demonstrate disorganized growth plates with increased late chondrocyte differentiation and retention of hypertrophic chondrocytes in the trabeculae. Taken together, our data suggest that Kindlin-3 expression is increased in a biphasic fashion during chondrocyte differentiation in a manner similar to RUNX2 (Figure 7).

Kindlin-3 may play a role in the balance between RUNX2 and SOX9

RUNX2 is the main transcription factor regulating chondrocyte hypertrophy and terminal differentiation (Chen et al., 2014; Inada et al., 1999). Our data demonstrate that Kindlin-3 expression increases in MSCs over time when exposed to chondrogenic media paralleling the increase in RUNX2 in culture. Additionally, in growth plates, Kindlin-3 was expressed early in resting chondrocytes and again in hypertrophic chondrocytes just prior to the ossification front. This pattern of expression is similar to RUNX2. Loss of Kindlin-3 allowed for initial chondrocyte differentiation of BMSCs and increased SOX9 production. Similarly, in mice with RUNX2 deficiencies, SOX9 and parathyroid hormone-related protein levels were equal to that of 
control mice, and early chondrogenesis proceeded normally (Amizuka et al., 1994). In fact, one study demonstrated that premature stimulation of chondrocyte hypertrophy in MSCs resulted in enhanced calcification and bone formation (Pelttari et al., 2006). This presents one potential mechanism for why the loss of Kindlin-3 induces osteopenia in patients. Since the BMSCs derived from patients had premature stimulation of chondrogenesis, they could induce excessive calcification and bone formation.

The balance of RUNX2 and SOX9 regulates chondrogenesis. While RUNX2 controls the initial differentiation from BMSC to chondrocyte and the later hypertrophic growth and terminal differentiation, SOX9 is required for early chondrogenesis and the initial transition into hypertrophy. SOX9 expressing pre-hypertrophic chondrocytes express $O s x, M M P 13, P T H r P$ and begin to upregulate RUNX2 to complete hypertrophy (Dy et al., 2012; Ikegami et al., 2011). RUNX2 regulation of chondrocyte maturation and hypertrophy requires it to suppress SOX9 activity in distinct stages of chondrocyte maturation (Cheng and Genever, 2010). Decreases in SOX9 expression are associated with longer hypertrophic zones and increased mineralization. Our data demonstrate that Kindlin-3 plays a role in the equilibrium between SOX9 and RUNX2. SOX9 blocks RUNX2 expression inhibiting hypertrophy and osteoblast differentiation in a dominant manner (Zhou et al., 2006). SOX9 upregulated Bapx1/Nkx3.2 suppresses RUNX2 in chondrocytes preventing late-stage chondrogenesis (Yamashita et al., 2009; Provot et al., 2006). Thus, the increase in SOX9 and decrease in RUNX2 in Kindlin-3 deficient BMSCs and the loss of integrin binding in the Kindlin-3 mutant mice results in faster progression through the early stages of chondrocyte differentiation but slows terminal differentiation resulting in the retention of chondrocyte cells in the ossification front. 
Kindlin's integrin binding function in the regulation of chondrogenesis

Downstream of SOX9 activation, chondrocytes begin to enhance their secretion of extracellular matrix proteins, requiring increased integrin activation and binding during the transition into hypertrophy (Quintana et al., 2009). The extreme changes in chondrocyte shape and ECM during chondrogenesis requires both inside-out and outside-in integrin signaling and activation. In the growth plate, chondrocytes undergo physical relocation and rotation requiring movement through the extracellular matrix, rearrangement of focal adhesions, and integrin activation. Chondrocyte adhesion and maturation is regulated by integrins, and integrin expression can be altered with maturation. Studies have suggested that integrin signaling, particularly through $\beta_{1}$ integrin, may have a temporal role during chondrogenesis. For example, $\alpha_{5} \beta_{1}$ integrin is expressed in the proliferative and hypertrophic zones (Enomoto-Iwamoto et al., 1997). The $\beta_{1}$ integrin controls later stages of chondrogenesis as inhibition of the $\beta_{1}$ integrininduced the expression of SOX9 and collagen type $\mathrm{X}$ at early time points (Lu et al., 2008). Further, $\beta_{1}$ integrin deletion in articular cartilage resulted in disorganized cartilage with disruption of the actin cytoskeleton and enhanced terminal differentiation (Raducanu et al., 2009). In our model of early chondrogenesis, we do not see a disruption of the actin cytoskeleton but rather an increase in actin formation. However the loss of integrin activation due to Kindlin-3 deficiency did accelerate differentiation. The effects are likely less pronounced since the other Kindlin isoforms are still able to perform their integrin binding function. In addition, the $\beta_{1}$ integrin-deficient articular cartilage demonstrated a thicker zone of calcified cartilage as demonstrated by collagen type X staining (Raducanu et al., 2009), similar to the increased collagen type $\mathrm{X}$ expression seen with Kindlin-3 mutation. MMP expression was not altered by loss of $\beta_{1}$ integrin expression in mesenchymal cells. Deletion of the $\beta_{1}$ integrin in mesenchymal 
cells results in chondrocyte clustering and structural disorganization. Expression of collagen type $X$ started earlier in the cartilage (Raducanu et al., 2009). Blocking integrin $\beta_{1}$ in adipose-derived stem cells cultured in control media upregulated collagen type X and SOX9 gene expression (Lu et al., 2008) similar to our findings with Kindlin-3 deletion indicating that blocking integrin activation induces a more prominent chondrogenic phenotype prior to induction with chondrogenic media.

In the patient described here, Kindlin-3 deficiency significantly affected integrin activation and chondrocyte hypertrophy. Using a constitutively activated integrin rescue, we determined that of integrin activation could rescue chondrocyte adhesion and prevent the excessive SOX9 expression. In concert, Kindlin-3 mutated growth plates in which integrin binding only was altered, chondrocyte hypertrophy was again affected and SOX9 expression enhanced. Taken together, these data demonstrated that the integrin binding of Kindlin-3 was responsible for the changes in chondrocyte differentiation. These data are in line with previous studies demonstrating that alterations in integrin binding proteins affected chondrogenesis. Deletion of integrin-linked kinase (ILK) results in shortened and disorganized growth plates due to decreased hypertrophic region due to abnormal chondrocyte proliferation and altered cell shape (Grashoff et al., 2003; Terpstra et al., 2003). Loss of ILK results in 30\% reduced chondrocyte adhesion to fibronectin and collagen type I (Grashoff et al., 2003) and 50\% to collagen type II (Terpstra et al., 2003). However, unlike the increased actin fiber formation seen in our study, ILK-deficient chondrocytes demonstrated fewer, shorter, and disorganized stress fibers (Grashoff et al., 2003). Further, proliferation was decreased in the ILK null chondrocytes in vivo. These discrepancies are partially due to studying the BMSCs prior to chondrogenic differentiation. Similar to our findings with Kindlin-3, expression of another integrin binding 
protein, vinculin in increased with chondrocyte maturation. Vinculin deletion in chondrogenic mesenchymal cells suppresses RUNX2, collagen type II, collagen type X, and aggrecan, but does not affect SOX9 expression. In addition, loss of vinculin resulted in disrupted columnar proliferation and decreased hypertrophy (Koshimizu et al., 2012).

Maturation of chondrocytes is associated with changes in the actin filament structure with chondrocyte dedifferentiation being associated with actin disruption (Benya et al., 1978; Zanetti and Solursh, 1984; Hirsch et al., 1996; Brown and Benya, 1988). Thus, changes in the actin cytoskeleton of BMSCs in monolayer may be representative of changes in chondrogenic differentiation similar to those seen with primary chondrocytes (Kerr et al., 2008). Disruptions in the actin cytoskeleton can also control chondrocyte maturation (Zanetti and Solursh, 1984; Kerr et al., 2008). MSCs treated with cytochalasin D to disrupt the actin network spontaneously undergo chondrogenesis. Thus, the diminished cell-matrix interactions caused by Kindlin-3 deficiency may promote a more chondrogenic phenotype in BMSCs. Kindlin-2 knockdown in pre-osteoblast cells resulted in decreased proliferation and spreading due to decreased activation of Rac1. However integrin expression and activation were unchanged (Jung et al., 2011). Correspondingly, Kindlin-3 regulates Rac1 activation downstream of integrin activation (Xue et al., 2013). Kindlin-3 regulation of integrin activation is required for cytoskeletal rearrangement. Kindlin deficient cells, platelets, in particular, have reduced spreading on a variety of substrates. One study demonstrated that Syk and Vav1 signaling downstream of integrin activation and Kindlin3 regulated Rac1 and Cdc42 to control cell spreading (Xue et al., 2013) Rac1 activation and subsequent reorganization of the actin cytoskeleton plays an important role in the transition to hypertrophy (Kerr et al., 2008).

Kindlins alter bone development beyond their roles in chondrogenesis 
A recent report of a new IADD (LAD-III) patient demonstrated that a loss of Kindlin-3 resulted in increased bone density with thickened cortices and trabeculae. Bars of calcified cartilage remained within the mature bone, and the hypertrophic cartilage was expanded with increased sclerotic areas. The cartilage below the proliferative zone was disorganized (Crazzolara et al., 2015). After BMT, the cartilage contained more mature cartilage tissue and reestablished columnar organization. A recent biopsy of an iliac crest from a patient with a Kindlin-3 mutation demonstrated abnormal osteoclasts numbers as well as cartilage remnants in the trabecular bone (Palagano et al., 2017). Another patient with a Kindlin-3 mutation displayed similar remnants of calcified cartilage in the trabecular bone as well as sclerotic primary spongiosa in the subchondral region (Crazzolara et al., 2015), which is similar to that seen in the K3KI mutant mice.

Our data demonstrate that Kindlin-3 and Kindlin-2 play opposing roles in the regulation of bone development. Kindlin-2 expression in MSCs during chondrogenesis was required for chondrocyte proliferation and development of the primary ossification center (Wu et al., 2015). We demonstrate that Kindlin-3 loss increased MSC proliferation and that Kindlin-3 was not expressed in proliferative chondrocytes in growth plates. Contrary to Kindlin-2, Kindlin-3 regulated chondrocyte hypertrophy. The two Kindlin proteins also interacted differently with the transcription factors associated with chondrocyte differentiation. The Kindlin-2 loss reduced SOX9 expression, while Kindlin-3 loss induced SOX9 expression in MSCs. Similar opposing effects were seen with collagen type II mRNA. These data indicated Kindlin-2 partners with SOX9 expression to drive early chondrocyte differentiation, while Kindlin-3 and RUNX2 regulate chondrocyte hypertrophy. Thus, Kindlin-3 and Kindlin-2 are expressed distinctly in 
MSCs and chondrocytes, and both orthologs are required for chondrogenesis to proceed normally.

There is also a potential role for Kindlins in osteogenesis since integrin activation is also integral to osteoblast differentiation. For example, $\alpha_{5}$ integrin promotes BMSC differentiation down the osteoblast lineage (Hamidouche et al., 2009). Overexpression or activation of $\alpha_{5}$ integrin-induced RUNX2, alkaline phosphatase, and collagen type I expression which controls the osteogenic lineage. Thus, an interaction between RUNX2 and integrin activation may control bone development. Inactivation of $\beta_{1}$ integrin in osteoblasts results in decreased bone mass (Zimmerman et al., 2000). In addition, the expression of integrins, including $\alpha_{5} \beta_{1}$, is required to drive osteoblast differentiation from human MSC (Hamidouche et al., 2009; Moursi et al., 1997). Deficiency of migfilin, a Kindlin binding protein, also results in severe osteopenia (Xiao et al., 2012; Brahme et al., 2013). Similar to our results, loss of migfilin resulted in decreased adhesion of MSCs (Brahme et al., 2013). Deletion of migfilin (filamin-binding LIM protein-1), another protein controlling integrin activation that binds to Kindlins, also induces osteopenia in mice. Similar to our data with the loss of Kindlin-3, migfilin deficiency in BMSCs lead to decreased cell adhesion to collagen type I and fibronectin (Xiao et al., 2012). BMSC differentiation into osteo-chondroprogenitor cells then chondrocytes. In addition to osteogenesis, Kindlin-3 has a known role in osteoclastogenesis. While, initial studies of Kindlin-3 in bone concentrated on the effect of Kindlin-3 in osteoclast function (Schmidt et al., 2011); their data also showed significantly decreased bone formation rate to bone surface area in Kindlin-3 deficient animals. Additionally, Kindlin-3 deficiency in patients alters the hematopoietic niche. Kindlin-3 expression in hematopoietic stem cells is required for their continued maintenance in the bone 
marrow (Ruppert et al., 2015). The inability of Kindlin-3 to bind integrins in our mice may result in alterations in crosstalk between MSCs and hematopoietic stem cells.

In summary, we demonstrate that Kindlin-3 plays an important role in the differentiation of mesenchymal stem cells down the chondrocyte lineage. This represents a potential secondary mechanism leading to osteopenia in Kindlin-3 deficient patients. Additional studies will need to be completed to understand the relationship between RUNX2, SOX9, and Kindlin-3 during chondrogenesis. 


\section{AUTHOR CONTRIBUTIONS}

Conceptualization: B.A.K., T.V.B.

Formal Analysis: B.A.K., L.S., A.H.J.

Funding Acquisition: T.V.B.

Investigation: B.A.K., L.S., A.H.J., D.P.L.

Project Administration: B.A.K, T.V.B

Resources: J.S.W., D.P.L., A.I.C.

Supervision: B.A.K., T.V.B., A.I.C.

Visualization: B.A.K., L.S.

Writing - Original Draft: B.A.K., T.V.B.

Writing - Review and Editing: B.A.K., L.S., A.H.J., J.S.W., D.P.L., A.I.C., T.V.B.

\section{ACKNOWLEDGEMENTS}

We acknowledge funding from NIH/NHLBI (HL073311 and HL071625) to Dr. Byzova.

Dr. Kerr was supported by a Ruth L. Kirschstein NRSA award (F32 CA142133) followed by a Pathway to Independence Award (K99 CA175291) from the NIH/NCI. We thank Joanna Ireland and Dr. Finke from the Department of Immunology for the gift of several FACS antibodies. We thank Dr. Sara Tomechko for assistance with the LiCor imaging and reagents and Dr. YoungWoong Kim for assistance with primer design. We thank Dr. Plow and his lab members for the gifts of fibrinogen, for the Kindlin-3 antibodies, and for their technical assistance. We thank Brandi Bickford of the Virtual Microscopy Core for her help with slide scanning. The authors declare no competing financial conflicts of interest. 


\section{REFERENCES}

Amizuka, N., H. Warshawsky, J.E. Henderson, D. Goltzman, and A.C. Karaplis. 1994.

Parathyroid hormone-related peptide-depleted mice show abnormal epiphyseal cartilage development and altered endochondral bone formation. J. Cell Biol. 126:1611-23. doi:10.1083/jcb.126.6.1611.

Benya, P.D., S.R. Padilla, and M.E. Nimni. 1978. Independent regulation of collagen types by chondrocytes during the loss of differentiated function in culture. Cell. 15:1313-21. doi:10.1016/0092-8674(78)90056-9.

Bialkowska, K., Y.-Q. Ma, K. Bledzka, K. Sossey-Alaoui, L. Izem, X. Zhang, N. Malinin, J. Qin, T. Byzova, and E.F. Plow. 2010. The integrin co-activator Kindlin-3 is expressed and functional in a non-hematopoietic cell, the endothelial cell. J. Biol. Chem. 285:18640-9. doi:10.1074/jbc.M109.085746.

Brahme, N.N., D.S. Harburger, K. Kemp-O'Brien, R. Stewart, S. Raghavan, M. Parsons, and D.A. Calderwood. 2013. Kindlin binds migfilin tandem LIM domains and regulates migfilin focal adhesion localization and recruitment dynamics. J Biol Chem. 288:35604-35616. doi:10.1074/jbc.M113.483016.

Brown, P.D., and P.D. Benya. 1988. Alterations in chondrocyte cytoskeletal architecture during phenotypic modulation by retinoic acid and dihydrocytochalasin B-induced reexpression. $J$. Cell Biol. 106:171-179. doi:10.1083/jcb.106.1.171.

Chen, H., F.Y. Ghori-Javed, H. Rashid, M.D. Adhami, R. Serra, S.E. Gutierrez, and A. Javed. 2014. Runx2 regulates endochondral ossification through control of chondrocyte 
proliferation and differentiation. J. Bone Miner. Res. 29:2653-65. doi:10.1002/jbmr.2287.

Cheng, A., and P.G. Genever. 2010. SOX9 determines RUNX2 transactivity by directing intracellular degradation. J Bone Min. Res. 25:2680-2689. doi:10.1002/jbmr.174.

Crazzolara, R., K. Maurer, H. Schulze, B. Zieger, J. Zustin, and A.S. Schulz. 2015. A new mutation in the KINDLIN-3 gene ablates integrin-dependent leukocyte, platelet, and osteoclast function in a patient with leukocyte adhesion deficiency-III. Pediatr. Blood Cancer. 62:1677-9. doi:10.1002/pbc.25537.

Dennis, J.E., E.K. Konstantakos, D. Arm, and A.I. Caplan. 1998. In vivo osteogenesis assay: a rapid method for quantitative analysis. Biomaterials. 19:1323-1328.

Dominici, M., K. Le Blanc, I. Mueller, I. Slaper-Cortenbach, F.. Marini, D.S. Krause, R.J. Deans, A. Keating, D. Prockop, and E.M. Horwitz. 2006. Minimal criteria for defining multipotent mesenchymal stromal cells. The International Society for Cellular Therapy position statement. Cytotherapy. 8:315-317. doi:10.1080/14653240600855905.

Dy, P., W. Wang, P. Bhattaram, Q. Wang, L. Wang, R.T. Ballock, and V. Lefebvre. 2012. Sox9 directs hypertrophic maturation and blocks osteoblast differentiation of growth plate chondrocytes. Dev Cell. 22:597-609. doi:10.1016/j.devcel.2011.12.024.

Enomoto-Iwamoto, M., M. Iwamoto, K. Nakashima, Y. Mukudai, D. Boettiger, M. Pacifici, K. Kurisu, and F. Suzuki. 1997. Involvement of alpha5beta1 integrin in matrix interactions and proliferation of chondrocytes. J. Bone Miner. Res. 12:1124-32. doi:10.1359/jbmr.1997.12.7.1124.

Fang, F., G. Orend, N. Watanabe, T. Hunter, and E. Ruoslahti. 1996. Dependence of cyclin E- 
CDK2 kinase activity on cell anchorage. Science. 271:499-502.

doi:10.1126/science.271.5248.499.

Grashoff, C., A. Aszódi, T. Sakai, E.B. Hunziker, and R. Fässler. 2003. Integrin-linked kinase regulates chondrocyte shape and proliferation. EMBO Rep. 4:432-8. doi:10.1038/sj.embor.embor801.

Hamidouche, Z., O. Fromigue, J. Ringe, T. Haupl, P. Vaudin, J.C. Pages, S. Srouji, E. Livne, and P.J. Marie. 2009. Priming integrin alpha5 promotes human mesenchymal stromal cell osteoblast differentiation and osteogenesis. Proc Natl Acad Sci U S A. 106:18587-18591. doi:10.1073/pnas.0812334106.

Häusler, G., M. Helmreich, S. Marlovits, and M. Egerbacher. 2002. Integrins and extracellular matrix proteins in the human childhood and adolescent growth plate. Calcif. Tissue Int. 71:212-8. doi:10.1007/s00223-001-2083-X.

Hirsch, M.S., S.C. Cook, R. Killiany, and K.K. Hartford Svoboda. 1996. Increased cell diameter precedes chondrocyte terminal differentiation, whereas cell-matrix attachment complex proteins appear constant. Anat. Rec. 244:284-296. doi:10.1002/(SICI)10970185(199603)244:3<284::AID-AR2>3.0.CO;2-Z.

Ikegami, D., H. Akiyama, A. Suzuki, T. Nakamura, T. Nakano, H. Yoshikawa, and N. Tsumaki. 2011. Sox9 sustains chondrocyte survival and hypertrophy in part through Pik3ca-Akt pathways. Development. 138:1507-19. doi:10.1242/dev.057802.

Inada, M., T. Yasui, S. Nomura, S. Miyake, K. Deguchi, M. Himeno, M. Sato, H. Yamagiwa, T. Kimura, N. Yasui, T. Ochi, N. Endo, Y. Kitamura, T. Kishimoto, and T. Komori. 1999. 
Maturational disturbance of chondrocytes in Cbfa1-deficient mice. Dev. Dyn. 214:279-90. doi:10.1002/(SICI)1097-0177(199904)214:4<279::AID-AJA1>3.0.CO;2-W.

Jones, M.C., J.A. Askari, J.D. Humphries, and M.J. Humphries. 2018. Cell adhesion is regulated by CDK1 during the cell cycle. J. Cell Biol. jcb.201802088. doi:10.1083/jcb.201802088.

Jung, G.-Y., Y.-J. Park, and J.-S. Han. 2011. Mediation of Rac1 activation by kindlin-2: an essential function in osteoblast adhesion, spreading, and proliferation. J. Cell. Biochem. 112:2541-8. doi:10.1002/jcb.23178.

Kerr, B.A., T. Otani, E. Koyama, T.A. Freeman, and M. Enomoto-Iwamoto. 2008. Small GTPase protein Rac-1 is activated with maturation and regulates cell morphology and function in chondrocytes. Exp. Cell Res. 314:1301-1312. doi:10.1016/j.yexcr.2007.12.029.

Koshimizu, T., M. Kawai, H. Kondou, K. Tachikawa, N. Sakai, K. Ozono, and T. Michigami. 2012. Vinculin functions as regulator of chondrogenesis. J. Biol. Chem. 287:15760-75. doi:10.1074/jbc.M111.308072.

Lennon, D.P., and A.I. Caplan. 2006. Isolation of human marrow-derived mesenchymal stem cells. Exp. Hematol. 34:1604-1605. doi:10.1016/j.exphem.2006.07.014.

Lennon, D.P., S.E. Haynesworth, R.G. Young, J.E. Dennis, and A.I. Caplan. 1995. A chemically defined medium supports in vitro proliferation and maintains the osteochondral potential of rat marrow-derived mesenchymal stem cells. Exp Cell Res. 219:211-222. doi:10.1006/excr.1995.1221.

Long, F., and D.M. Ornitz. 2013. Development of the endochondral skeleton. Cold Spring Harb. Perspect. Biol. 5:1-20. doi:10.1101/cshperspect.a008334. 
Lu, Z.F., B. Zandieh Doulabi, C.L. Huang, R.A. Bank, and M.N. Helder. 2008. Beta1 integrins regulate chondrogenesis and rock signaling in adipose stem cells. Biochem. Biophys. Res. Commun. 372:547-52. doi:10.1016/j.bbrc.2008.05.063.

Mackie, E.J., Y.A. Ahmed, L. Tatarczuch, K.S. Chen, and M. Mirams. 2008. Endochondral ossification: how cartilage is converted into bone in the developing skeleton. Int J Biochem Cell Biol. 40:46-62. doi:10.1016/j.biocel.2007.06.009.

Majumdar, M.K., M. Keane-Moore, D. Buyaner, W.B. Hardy, M.A. Moorman, K.R. McIntosh, J.D. Mosca, P. Charbord, D. Noël, C. Jorgensen, and C. Kahn. 2003. Characterization and functionality of cell surface molecules on human mesenchymal stem cells. J. Biomed. Sci. 10:228-241. doi:10.1007/BF02256058.

Malinin, N.L., L. Zhang, J. Choi, A. Ciocea, O. Razorenova, Y.Q. Ma, E.A. Podrez, M. Tosi, D.P. Lennon, A.I. Caplan, S.B. Shurin, E.F. Plow, and T. V Byzova. 2009. A point mutation in KINDLIN3 ablates activation of three integrin subfamilies in humans. Nat Med. 15:313318. doi:10.1038/nm.1917.

Matus, D.Q., E. Chang, S.C. Makohon-Moore, M.A. Hagedorn, Q. Chi, and D.R. Sherwood. 2014. Cell division and targeted cell cycle arrest opens and stabilizes basement membrane gaps. Nat. Commun. 5:4184. doi:10.1038/ncomms5184.

McCabe, N.P., S. De, A. Vasanji, J. Brainard, and T. V Byzova. 2007. Prostate cancer specific integrin $\alpha v \beta 3$ modulates bone metastatic growth and tissue remodeling. Oncogene. 26:6238-6243. doi:10.1038/sj.onc.1210429.

McCabe, N.P., B.A. Kerr, M. Madajka, A. Vasanji, and T. V Byzova. 2011. Augmented 
osteolysis in SPARC-deficient mice with bone-residing prostate cancer. Neoplasia. 13:319. doi:10.1593/neo.10998.

Meller, J., Z. Chen, T. Dudiki, R.M. Cull, R. Murtazina, S.K. Bal, E. Pluskota, S. Stefl, E.F. Plow, B.D. Trapp, and T. V. Byzova. 2017. Integrin-Kindlin3 requirements for microglial motility in vivo are distinct from those for macrophages. JCI insight. 2:e93002. doi:10.1172/jci.insight.93002.

Moser, M., B. Nieswandt, S. Ussar, M. Pozgajova, and R. Fassler. 2008. Kindlin-3 is essential for integrin activation and platelet aggregation. Nat Med. 14:325-330. doi:10.1038/nm1722.

Moursi, A.M., R.K. Globus, and C.H. Damsky. 1997. Interactions between integrin receptors and fibronectin are required for calvarial osteoblast differentiation in vitro. J Cell Sci. 110 ( Pt 1:2187-2196.

Palagano, E., M.A. Slatter, P. Uva, C. Menale, A. Villa, M. Abinun, and C. Sobacchi. 2017. Hematopoietic stem cell transplantation corrects osteopetrosis in a child carrying a novel homozygous mutation in the FERMT3 gene. Bone. 97:126-129. doi:10.1016/j.bone.2017.01.012.

Pelttari, K., A. Winter, E. Steck, K. Goetzke, T. Hennig, B.G. Ochs, T. Aigner, and W. Richter. 2006. Premature induction of hypertrophy during in vitro chondrogenesis of human mesenchymal stem cells correlates with calcification and vascular invasion after ectopic transplantation in SCID mice. Arthritis Rheum. 54:3254-3266. doi:10.1002/art.22136.

Plow, E.F., J. Qin, and T. Byzova. 2009. Kindling the flame of integrin activation and function with kindlins. Curr Opin Hematol. 16:323-328. doi:10.1097/MOH.0b013e32832ea389. 
Provot, S., H. Kempf, L.C. Murtaugh, U. Chung, D.-W. Kim, J. Chyung, H.M. Kronenberg, and A.B. Lassar. 2006. Nkx3.2/Bapx1 acts as a negative regulator of chondrocyte maturation. Development. 133:651-62. doi:10.1242/dev.02258.

Quintana, L., N.I. zur Nieden, and C.E. Semino. 2009. Morphogenetic and regulatory mechanisms during developmental chondrogenesis: new paradigms for cartilage tissue engineering. Tissue Eng Part B Rev. 15:29-41. doi:10.1089/ten.teb.2008.0329.

Raducanu, A., E.B. Hunziker, I. Drosse, and A. Aszódi. 2009. Beta1 integrin deficiency results in multiple abnormalities of the knee joint. J. Biol. Chem. 284:23780-92. doi:10.1074/jbc.M109.039347.

Ruppert, R., M. Moser, M. Sperandio, E. Rognoni, M. Orban, W.H. Liu, A.S. Schulz, R.A. Oostendorp, S. Massberg, and R. Fassler. 2015. Kindlin-3-mediated integrin adhesion is dispensable for quiescent but essential for activated hematopoietic stem cells. J Exp Med. 212:1415-1432. doi:10.1084/jem.20150269.

Sabnis, H., A. Kirpalani, J. Horan, A. McDowall, L. Svensson, A. Cooley, T. Merck, S. Jobe, N. Hogg, and M. Briones. 2010. Leukocyte adhesion deficiency-III in an African-American patient. Pediatr. Blood Cancer. 55:180-2. doi:10.1002/pbc.22386.

Schmidt, S., I. Nakchbandi, R. Ruppert, N. Kawelke, M.W. Hess, K. Pfaller, P. Jurdic, R. Fassler, and M. Moser. 2011. Kindlin-3-mediated signaling from multiple integrin classes is required for osteoclast-mediated bone resorption. J Cell Biol. 192:883-897. doi:10.1083/jcb.201007141.

Solchaga, L.A., J.F. Welter, D.P. Lennon, and A.I. Caplan. 2004. Generation of pluripotent stem 
cells and their differentiation to the chondrocytic phenotype. Methods Mol. Med. 100:5368. doi:10.1385/1-59259-810-2:053.

Solursh, M., T.F. Linsenmayer, and K.L. Jensen. 1982. Chondrogenesis from single limb mesenchyme cells. Dev. Biol. 94:259-264. doi:10.1016/0012-1606(82)90090-2.

Terpstra, L., J. Prud'homme, A. Arabian, S. Takeda, G. Karsenty, S. Dedhar, and R. St-Arnaud. 2003. Reduced chondrocyte proliferation and chondrodysplasia in mice lacking the integrinlinked kinase in chondrocytes. J Cell Biol. 162:139-148. doi:10.1083/jcb.200302066.

Uckan, D., E. Kilic, P. Sharafi, M. Kazik, F. Kaya, E. Erdemli, A. Can, A. Tezcaner, and C. Kocaefe. 2009. Adipocyte differentiation defect in mesenchymal stromal cells of patients with malignant infantile osteopetrosis. Cytotherapy. 11:392-402. doi:10.1080/14653240802582083.

Ussar, S., H.-V. Wang, S. Linder, R. Fässler, and M. Moser. 2006. The Kindlins: subcellular localization and expression during murine development. Exp. Cell Res. 312:3142-51. doi:10.1016/j.yexcr.2006.06.030.

Wu, C., H. Jiao, Y. Lai, W. Zheng, K. Chen, H. Qu, W. Deng, P. Song, K. Zhu, H. Cao, D.L. Galson, J. Fan, H.-J. Im, Y. Liu, J. Chen, D. Chen, and G. Xiao. 2015. Kindlin-2 controls TGF- $\beta$ signalling and Sox9 expression to regulate chondrogenesis. Nat. Commun. 6:7531. doi:10.1038/ncomms8531.

Xiao, G., H. Cheng, H. Cao, K. Chen, Y. Tu, S. Yu, H. Jiao, S. Yang, H.J. Im, D. Chen, J. Chen, and C. Wu. 2012. Critical role of filamin-binding LIM protein 1 (FBLP-1)/migfilin in regulation of bone remodeling. J Biol Chem. 287:21450-21460. 
doi:10.1074/jbc.M111.331249.

Xu, Z., J. Cai, J. Gao, G.C. White 2nd, F. Chen, and Y.Q. Ma. 2015. Interaction of kindlin-3 and beta2-integrins differentially regulates neutrophil recruitment and NET release in mice. Blood. 126:373-377. doi:10.1182/blood-2015-03-636720.

Xu, Z., X. Chen, H. Zhi, J. Gao, K. Bialkowska, T. V Byzova, E. Pluskota, G.C. White 2nd, J. Liu, E.F. Plow, and Y.Q. Ma. 2014. Direct interaction of kindlin-3 with integrin alphaIlbbeta3 in platelets is required for supporting arterial thrombosis in mice. Arter. Thromb Vasc Biol. 34:1961-1967. doi:10.1161/ATVBAHA.114.303851.

Xue, Z.H., C. Feng, W.L. Liu, and S.M. Tan. 2013. A role of kindlin-3 in integrin alphaMbeta2 outside-in signaling and the Syk-Vav1-Rac1/Cdc42 signaling axis. PLoS One. 8:e56911. doi:10.1371/journal.pone.0056911.

Yamashita, S., M. Andoh, H. Ueno-Kudoh, T. Sato, S. Miyaki, and H. Asahara. 2009. Sox9 directly promotes Bapx 1 gene expression to repress Runx2 in chondrocytes. Exp Cell Res. 315:2231-2240. doi:10.1016/j.yexcr.2009.03.008.

Yarali, N., T. Fişgin, F. Duru, and A. Kara. 2003. Osteopetrosis and Glanzmann’s thrombasthenia in a child. Ann. Hematol. 82:254-6. doi:10.1007/s00277-002-0571-3.

Zanetti, N.C., and M. Solursh. 1984. Induction of chondrogenesis in limb mesenchymal cultures by disruption of the actin cytoskeleton. J. Cell Biol. 99:115-23. doi:10.1083/JCB.99.1.115.

Zhou, G., Q. Zheng, F. Engin, E. Munivez, Y. Chen, E. Sebald, D. Krakow, and B. Lee. 2006. Dominance of SOX9 function over RUNX2 during skeletogenesis. Proc. Natl. Acad. Sci. U. S. A. 103:19004-9. doi:10.1073/pnas.0605170103. 
bioRxiv preprint doi: https://doi org/101101/578690; this version posted March 15, 2019. The copyright holder for this preprint (which was not certified by peer review) is the author/funder, who has granted bioRxiv a license to display the preprint in perpetuity. It is made available under aCC-BY-NC 4.0 International license.

Zimmerman, D., F. Jin, P. Leboy, S. Hardy, and C. Damsky. 2000. Impaired bone formation in transgenic mice resulting from altered integrin function in osteoblasts. Dev. Biol. 220:2-15. doi:10.1006/dbio.2000.9633. 
Table 1. Primers for qPCR.

\begin{tabular}{|c|c|c|c|}
\hline Gene & Forward & Reverse & $\begin{array}{l}\text { Product } \\
\text { Size }\end{array}$ \\
\hline $\begin{array}{l}\text { Kindlin-3/ } \\
\text { FERMT3 }\end{array}$ & GCATTTCACCTGCTGTCACT & ATCTGGTCTTCCTTGTGTGCT & 191 \\
\hline GAPDH & ACTTTGGTATCGTGGAAGGAC & AGTAGAGGCAGGGATGATGTT & 134 \\
\hline RUNX2 & CAGAAGGGAGGAGATGTGTGT & TCAAGGTTTGGAAGAAGTGTC & 170 \\
\hline SOX9 & CCTTTTTGTCCATCCCTTTT & AAACACACACACACCCACAC & 181 \\
\hline$M M P 7$ & GTCTCTGGACGGCAGCTATG & TAGTCCTGAGCCTGTTCCCA & 130 \\
\hline$M M P 13$ & CATGAGTTCGGCCACTCCTT & CCTCGGAGACTGGTAATGGC & 230 \\
\hline$O S X$ & GAGAGGAGAGACTCGGGACA & AGTTGTTGAGTCCCGCAGAG & 202 \\
\hline$I B S P$ & AAGGGCACCTCGAAGACAAC & CCCTCGTATTCAACGGTGGT & 119 \\
\hline$A C A N$ & GACCTGTCTGGTCACACCTC & TCACATACCTCCTGGTCTGC & 248 \\
\hline FGFR3 & AGCAGCTCACCTTCAAGGAC & GGCCGTTGGTTGTCTTCTTG & 204 \\
\hline COL2A1 & AAACCTGAACCCAGAAACAAC & AAAGAGAGGGGAGAAAAGTCC & 157 \\
\hline$B M P 2$ & ACTCGAAATTCCCCGTGACC & CCACTTCCACCACGAATCCA & 144 \\
\hline COL9A1 & AACAGTGAAGGGGTCGTGAG & AATTGACAGGGAATCTGGGGC & 193 \\
\hline $\begin{array}{l}B A P X 1 / \\
N K X 3-2\end{array}$ & ACCGAGACGCAGGTGAAAAT & CACCTTTACGGCCACCTTCT & 117 \\
\hline $\begin{array}{l}\text { PTHrP } \\
\text { /PTHLH }\end{array}$ & TCGAGGTTCAAAGGTTTGCC & GTGTGTCGTCGATCAGGAGG & 189 \\
\hline HPRT1 & GCCAGACTTTGTTGGATTTG & GGCTTTGTATTTTGCTTTTCC & 130 \\
\hline $\begin{array}{l}\text { Kindlin- } \\
\text { 2/FERMT2 }\end{array}$ & ATTAGTCCGTCGTGCTTGATT & AGACAGTGATTATGCTGGTGA & 124 \\
\hline
\end{tabular}




\section{FIGURE LEGENDS}

\section{Figure 1. Kindlin-3 is upregulated with chondrogenic differentiation in BMSCs and growth}

plates. BMSC isolated from normal patients were treated with control (open bars) or chondrogenic (patterned bars) media for 7 (A-C) or 14 days (B-C). (A) Cells were grown on 10 $\mu \mathrm{g} / \mathrm{mL}$ collagen type I coated glass coverslips were permeabilized and stained for actin (red), Kindlin-3 (green) or nuclei (blue). Mean fluorescence intensity of actin and Kindlin-3 were measured and represented as mean per cell \pm SEM. (B-C) Gene expression of Kindlin-3 (B) or RUNX2 (C) normalized to GAPDH represented as mean fold change from control media \pm SEM. (D) Sections of 9-week WT mice bones stained for hematoxylin \& eosin (H\&E), Collagen type II, Collagen type X, SOX9, and Kindlin-3. Scale bars represent $500 \mu \mathrm{m}$ (top) and $250 \mu \mathrm{m}$ (bottom). ${ }^{* *}$ represents $\mathrm{p}<0.01$ and $* * *$ represents $\mathrm{p}<0.005$ by Student's $t$ test (A) or one-way ANOVA (B-C).

Figure 2. Kindlin-3 deficiency inhibits substrate adhesion but stimulates proliferation. BMSC from normal controls or the Kindlin-3 deficient subject were plated on $10 \mu \mathrm{g} / \mathrm{mL}$ collagen type I, $10 \mu \mathrm{g} / \mathrm{mL}$ collagen type II, $10 \mu \mathrm{g} / \mathrm{mL}$ fibronectin, or $10 \mu \mathrm{g} / \mathrm{mL}$ vitronectin with tissue culture plastic coated with BSA as a control. (A) Adherence of cells to the substrates was measured after 30 minutes and represented as fold change from BSA control+SEM. (B-D) The proliferation of BMSC was measured over 5 days and represented as fold change from day $0 \pm$ SEM. * represents $\mathrm{p}<0.05, * *$ represents $\mathrm{p}<0.01$, and $* * *$ represents $\mathrm{p}<0.005$ by Student's $t$ test.

Figure 3. Kindlin-3 deficiency enhances chondrogenesis. BMSC from normal controls (white bars) or the Kindlin-3 deficient subject (black bars) were treated with either control (open bars) 
or chondrogenic (patterned bars) media. (A) Alcian Blue staining was measured after 12 days and represented as mean percent of control densitometry \pm SEM. (B) Alkaline Phosphatase staining was measured after 12 days and represented as mean percent of control densitometry \pm SEM. (C) Alkaline phosphatase activity was assessed biochemically and represented as mean concentration per $\mu \mathrm{g}$ DNA \pm SEM. (D) Gene expression of SOX9 normalized to $G A P D H$ represented as mean fold change from control media \pm SEM. * represents $\mathrm{p}<0.05, * *$ represents $\mathrm{p}<0.01$, and $* * *$ represents $\mathrm{p}<0.005$ by one-way ANOVA.

Figure 4. Kindlin-3 deficient BMSCs are further along the pathway towards chondrogenesis. BMSC from normal controls (white bars) or the Kindlin-3 deficient subject (black bars) were maintained in control, growth media. (A-D) Gene expression of the labeled genes was normalized to $G A P D H$ represented as mean fold change from control media \pm SEM. * represents $\mathrm{p}<0.05$, ** represents $\mathrm{p}<0.01$, and $* * *$ represents $\mathrm{p}<0.005$ by Student's $t$ test.

\section{Figure 5. Constitutively active $\beta 3$ integrin expression rescues Kindlin-3 deficient} attachment and chondrogenesis. BMSC from the Kindlin-3 deficient subject were transfected with either control WT $\beta 3$ integrin (white bars) or constitutively active DR $\beta 3$ integrin (black bars). (A) Cell attachment was measured as mean as fold change from BSA control \pm SEM. (B) BMSC were treated with control (open bars) or chondrogenic (patterned bars) media. Gene expression of SOX9 normalized to HPRT1 represented as mean fold change from control media \pm SEM. * represents $\mathrm{p}<0.05$, ** represents $\mathrm{p}<0.01$, and $* * *$ represents $\mathrm{p}<0.005$ by Student's $t$ test.

Figure 6. Blocking Kindlin-3 integrin binding results in growth plate abnormalities. Hindlimbs from 9-week old K3KI mutant and wild-type (WT) mice were sectioned and stained 
with (A) pentachrome or safranin $\mathrm{O}$ counterstained with fast green to visualize the growth plate area. Scale bars represent $1 \mathrm{~mm}$. (B) Hindlimbs were also immunostained for SOX9, Collagen type II, and Collagen type X and the numbers of cells stained per total cells in the growth plate calculated as mean \pm SEM. * represents $\mathrm{p}<0.05$ and $* *$ represents $\mathrm{p}<0.01$ by Student's $t$ test.

Figure 7. Kindlin-3 Expression during chondrogenesis. As BMSCs differentiate into hypertrophic chondrocytes changes in SOX9 and RUNX2 expression drive changes in differentiation marker expression. The effects of Kindlin-3 deficiency closely resemble a decrease in RUNX2 expression and, thus Kindlin-3 likely has biphasic expression during chondrogenesis. 
A

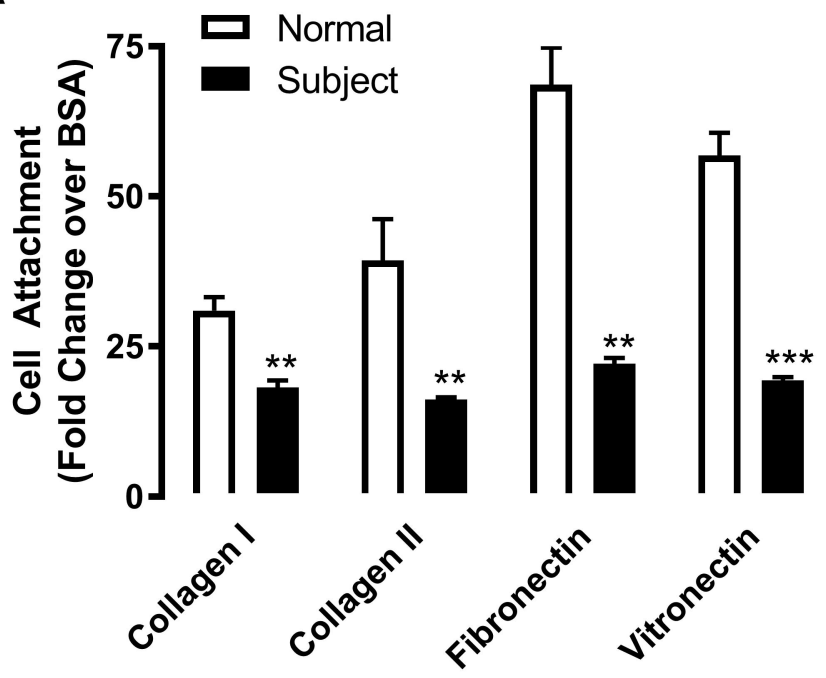

C

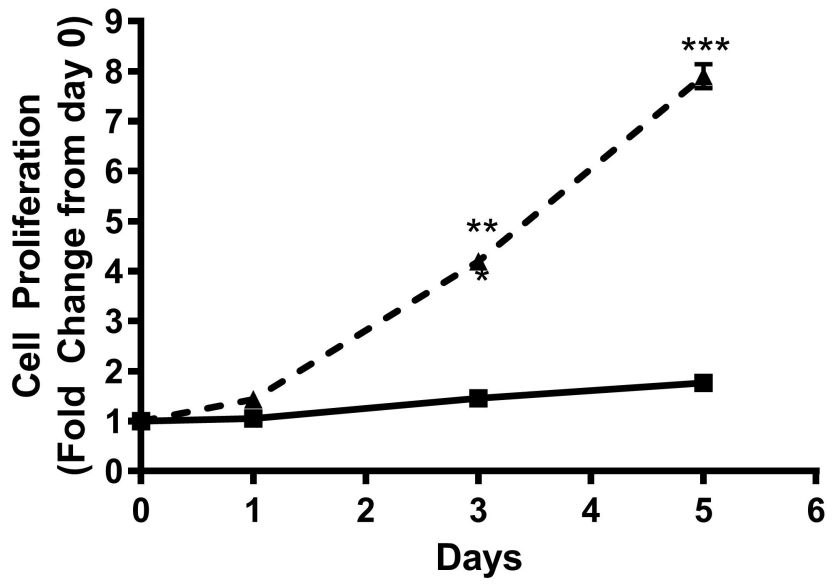

E

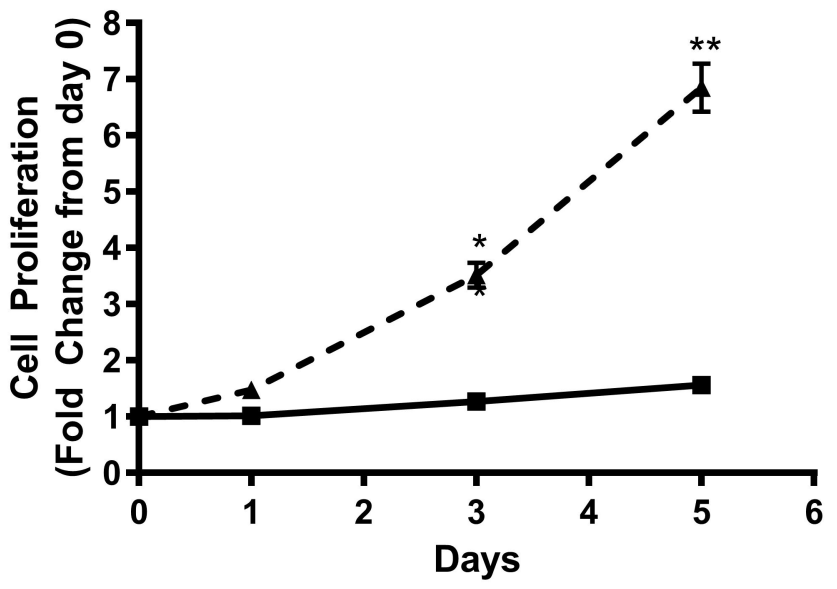

B

Tissue Culture Plastic

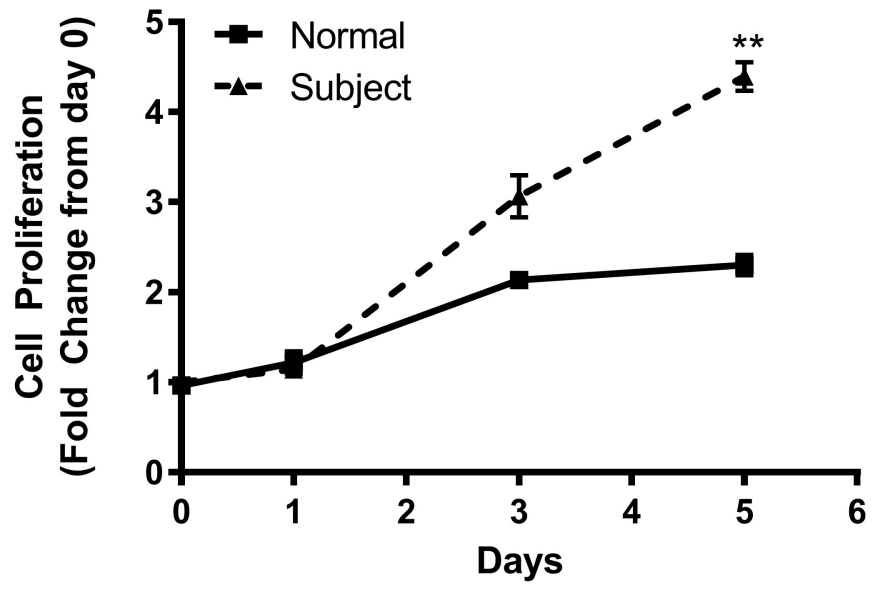

D

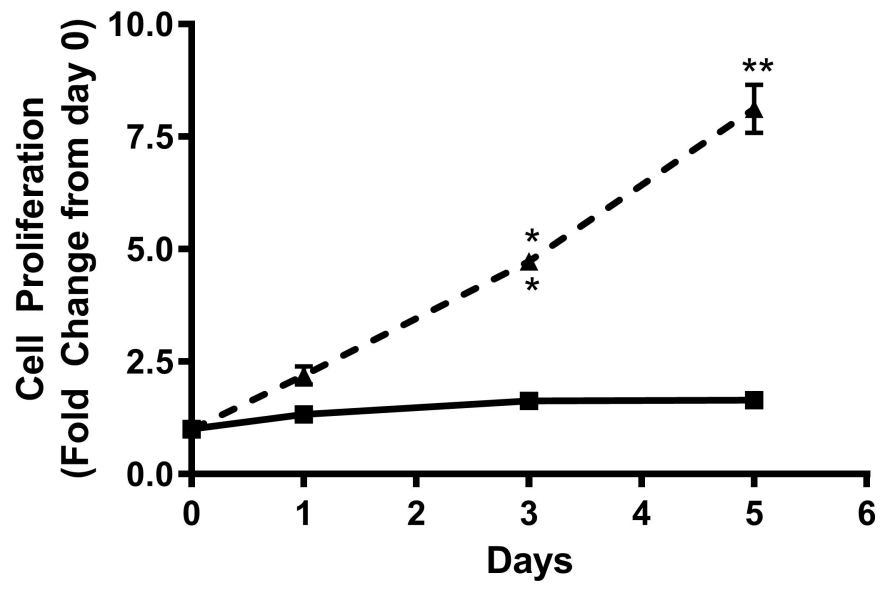

$\mathbf{F}$

Vitronectin

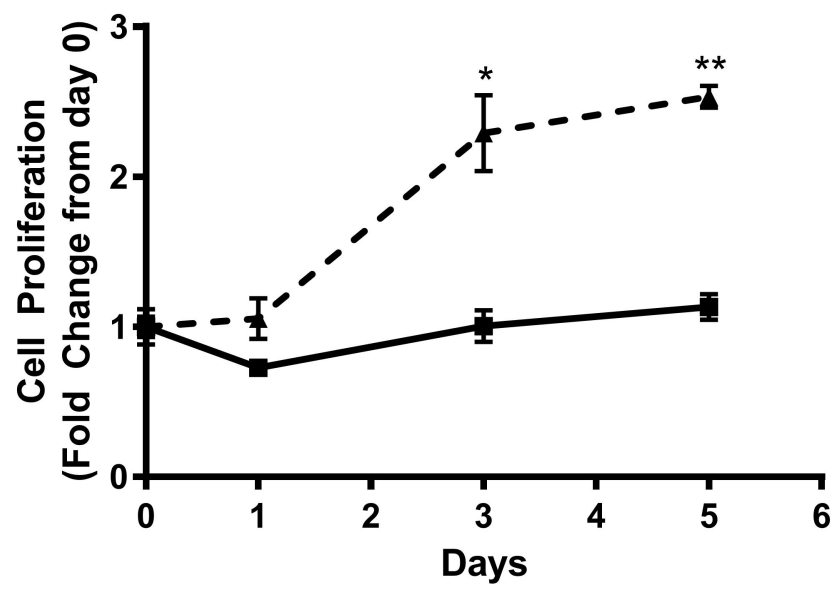


A

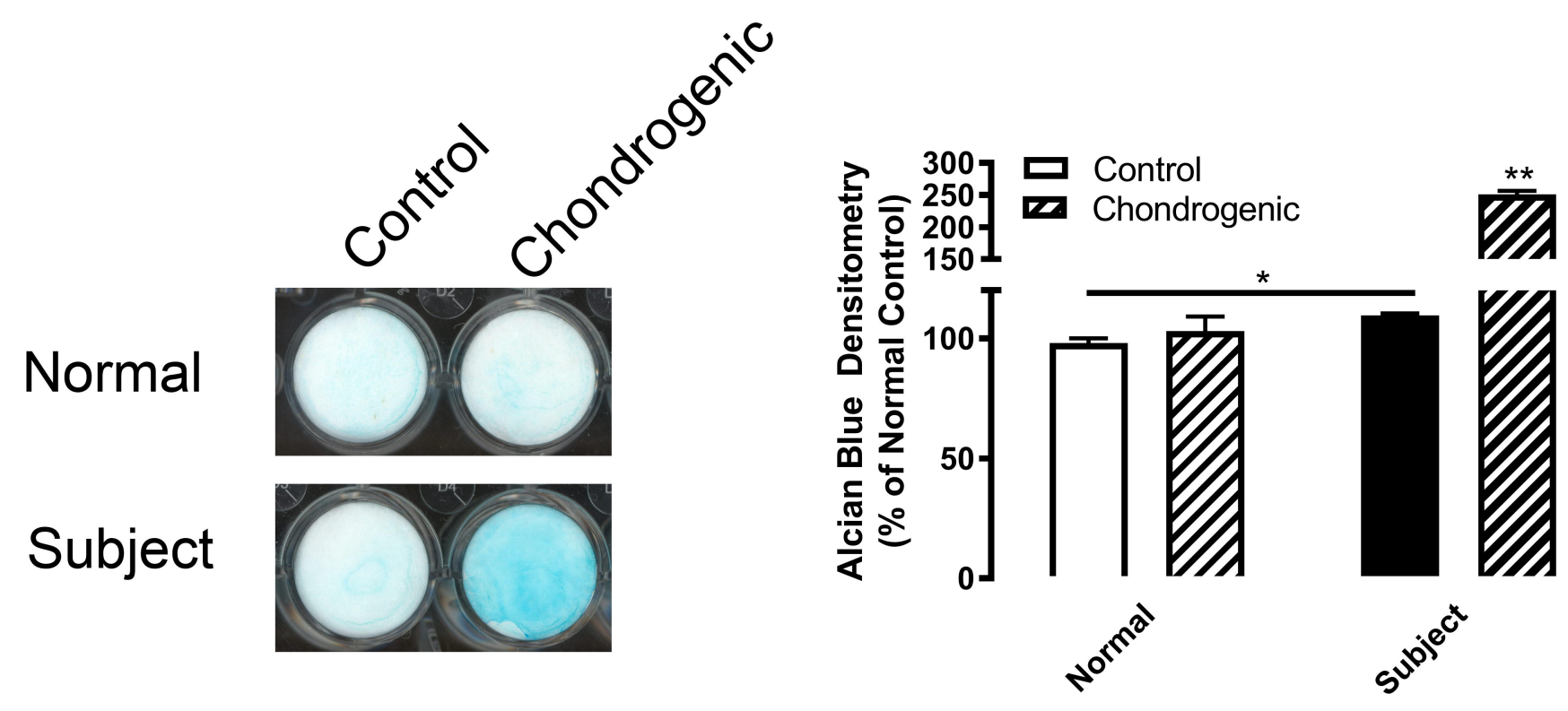

B

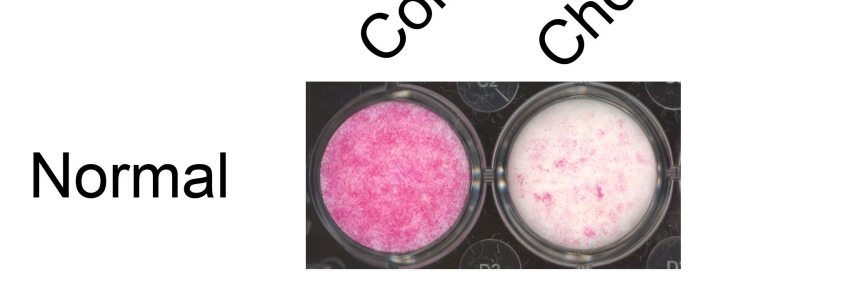

Subject
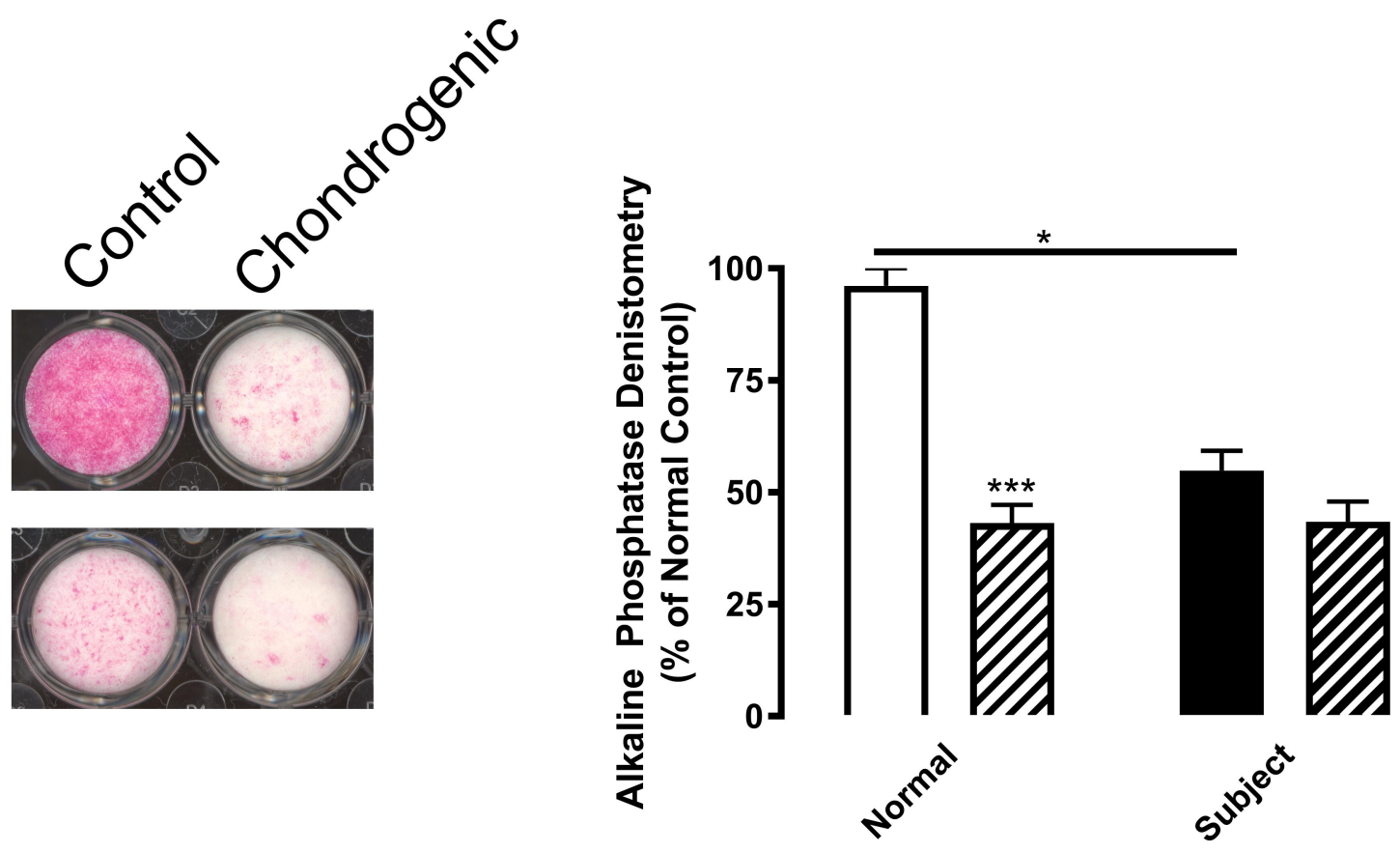

D

\%
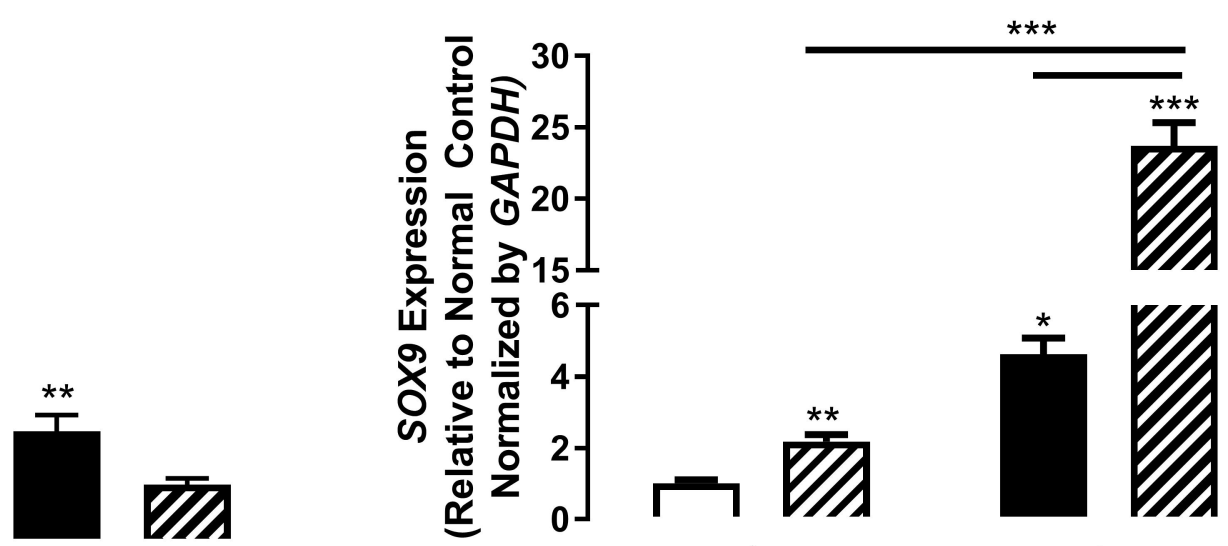

0.0
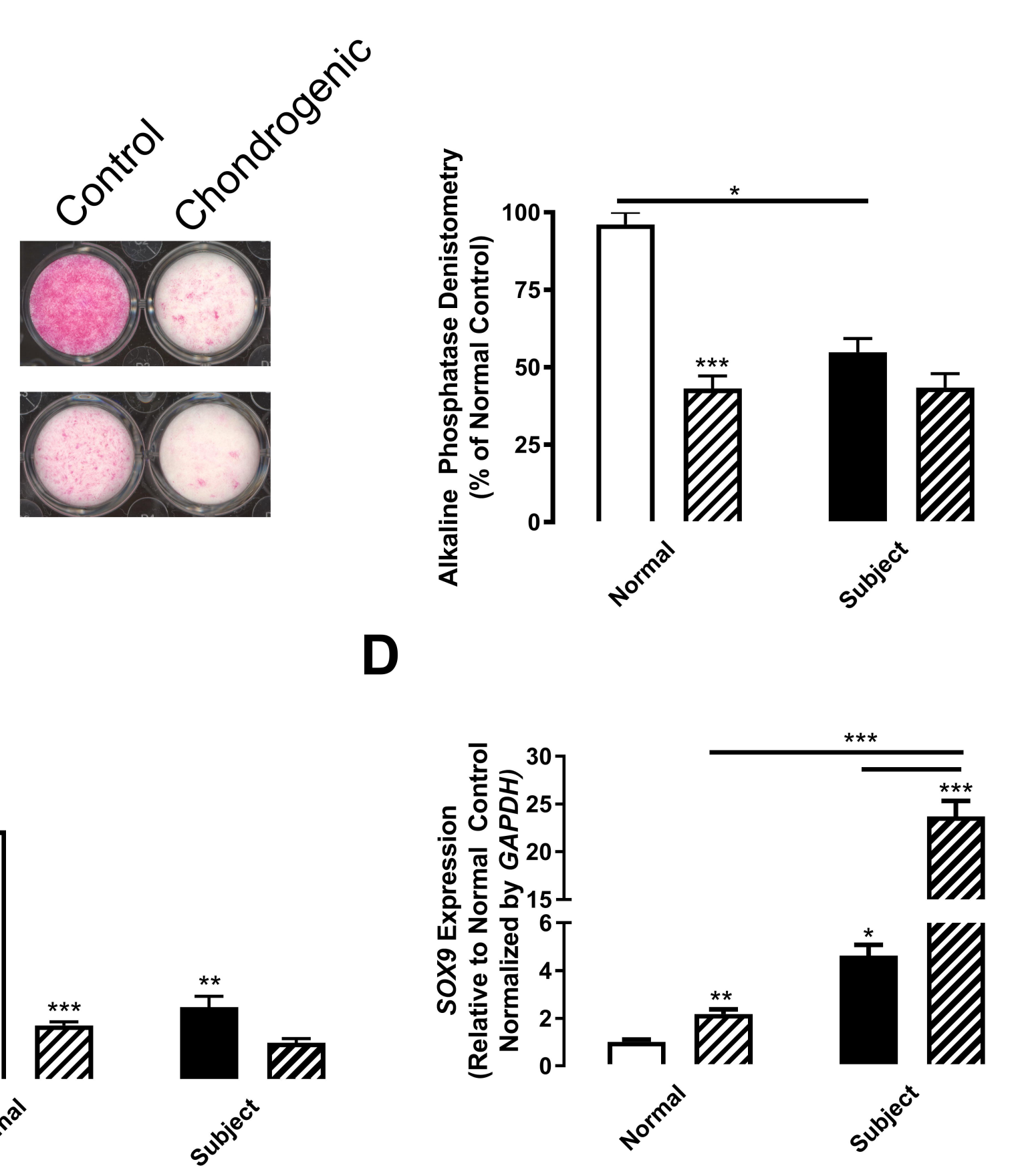
A

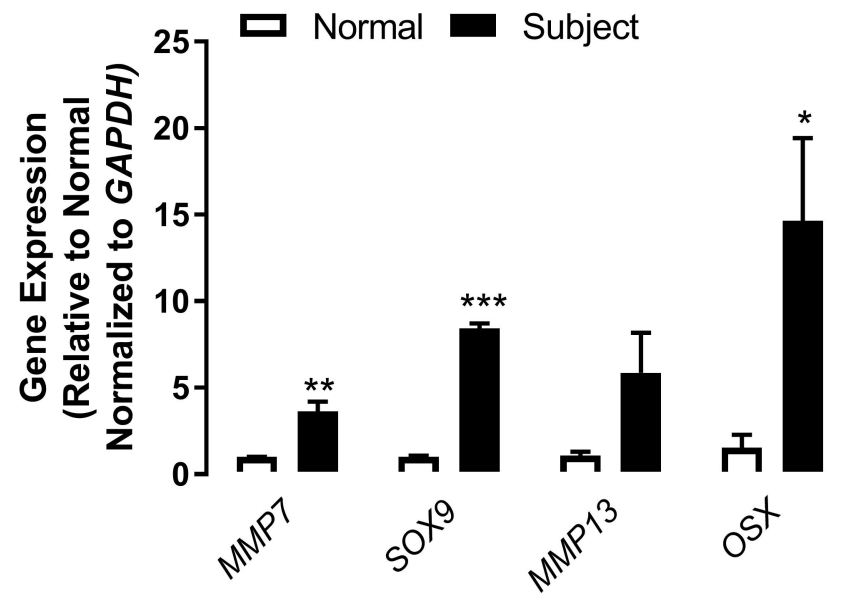

C

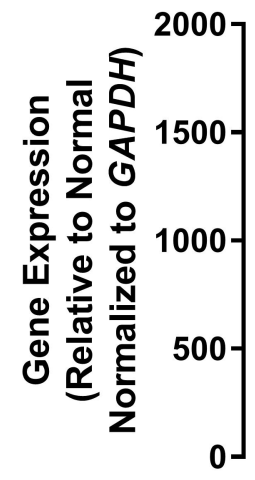

B

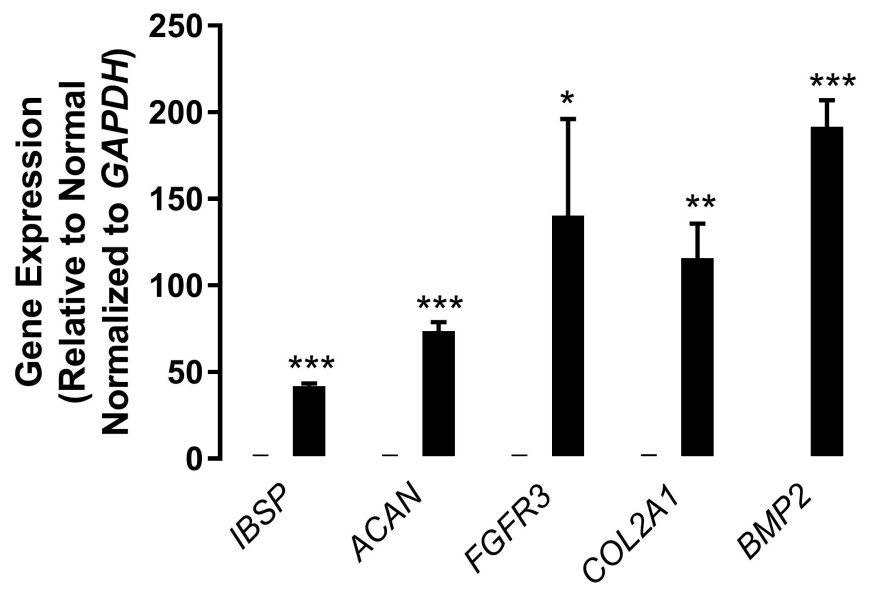

D

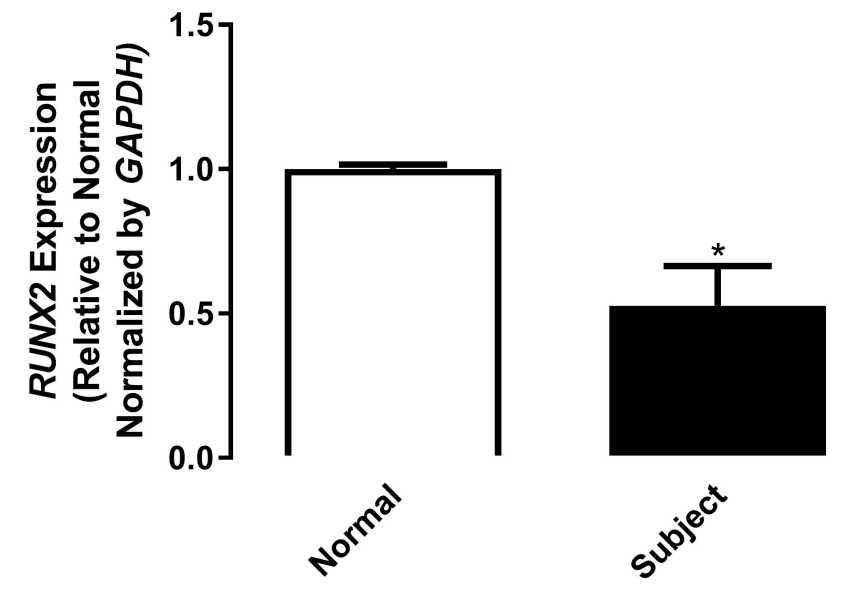



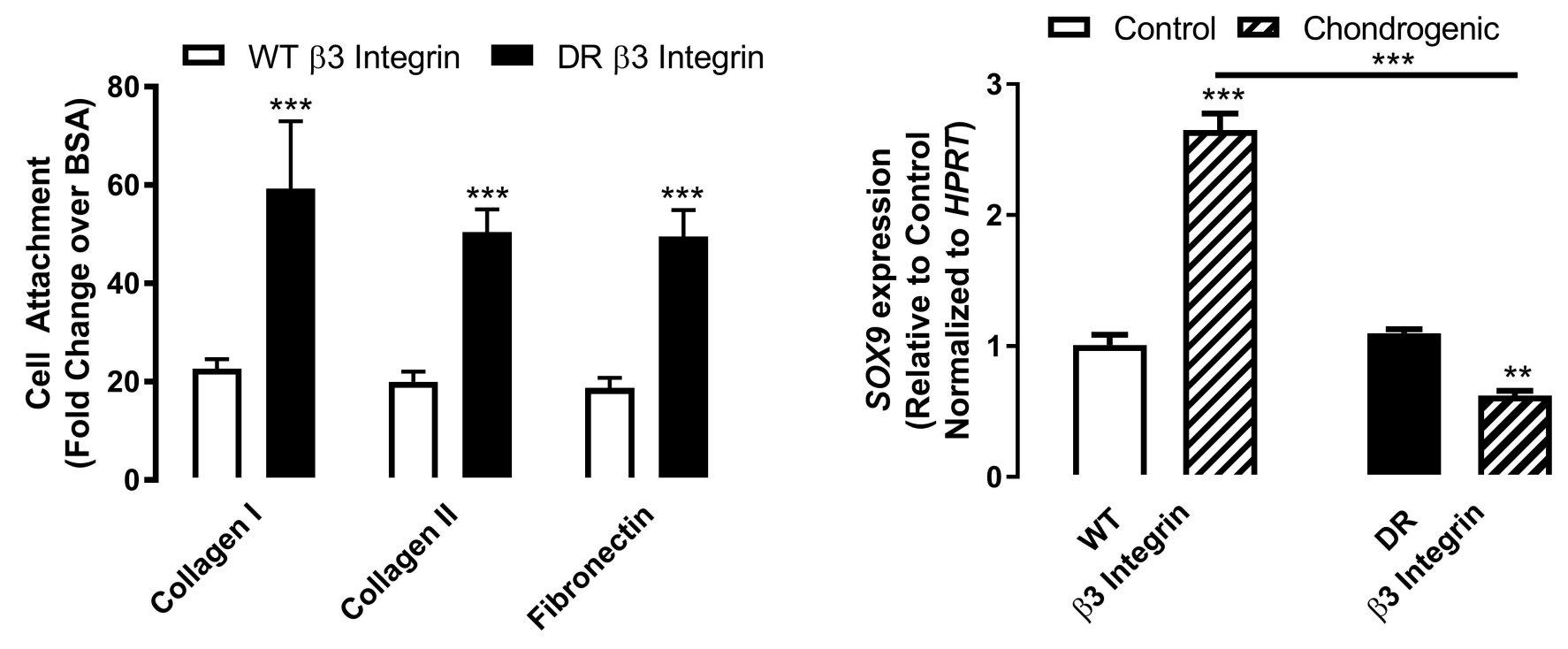
A

WT

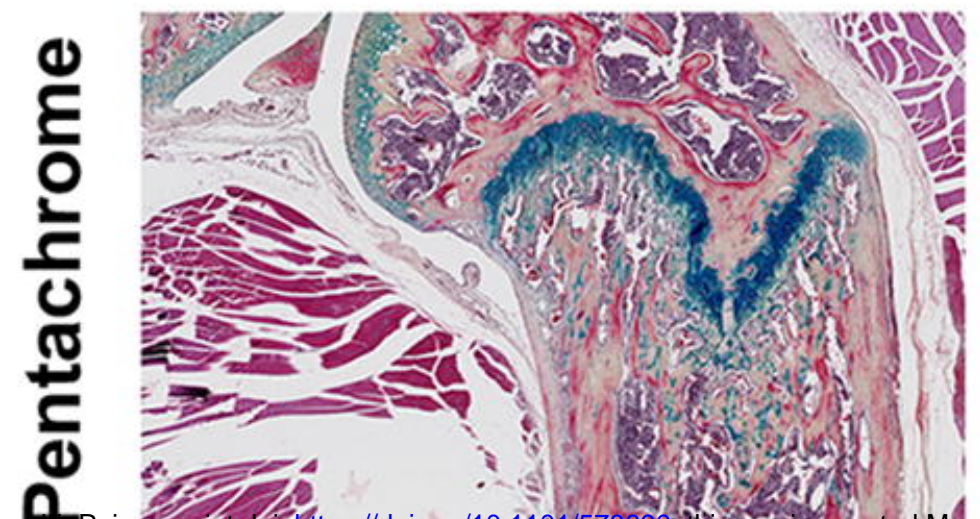

certified

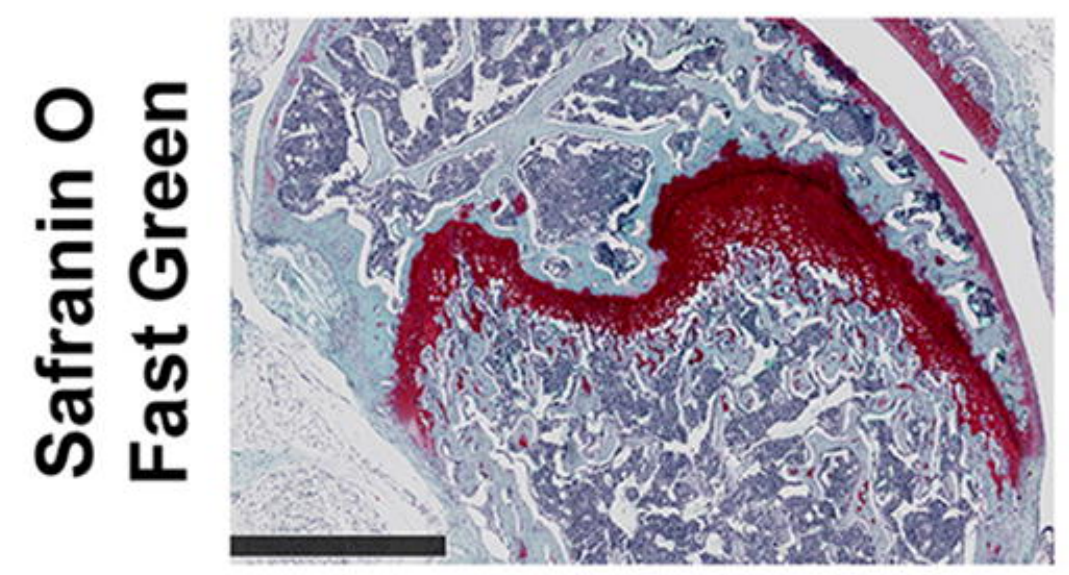

B
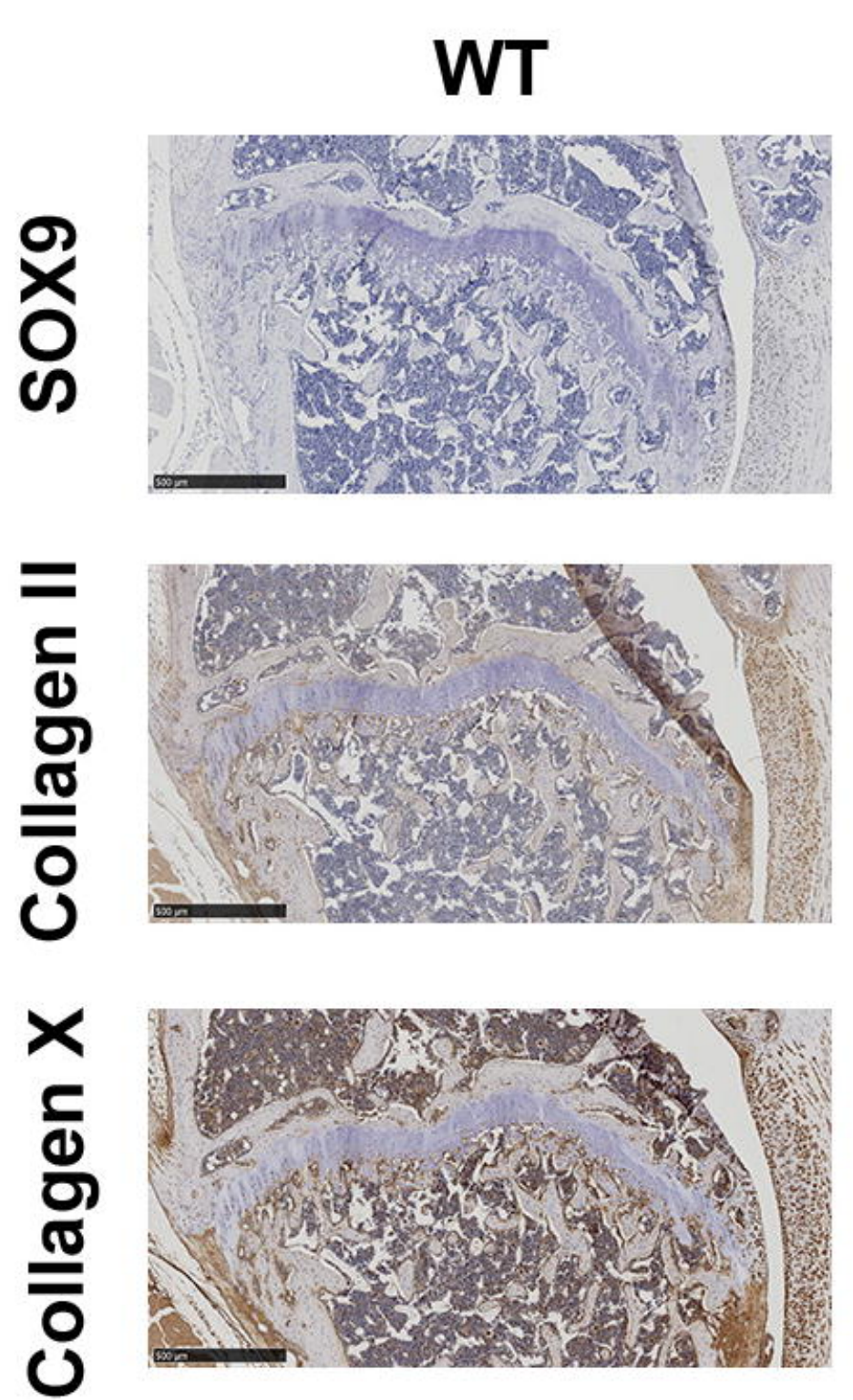

K3KI
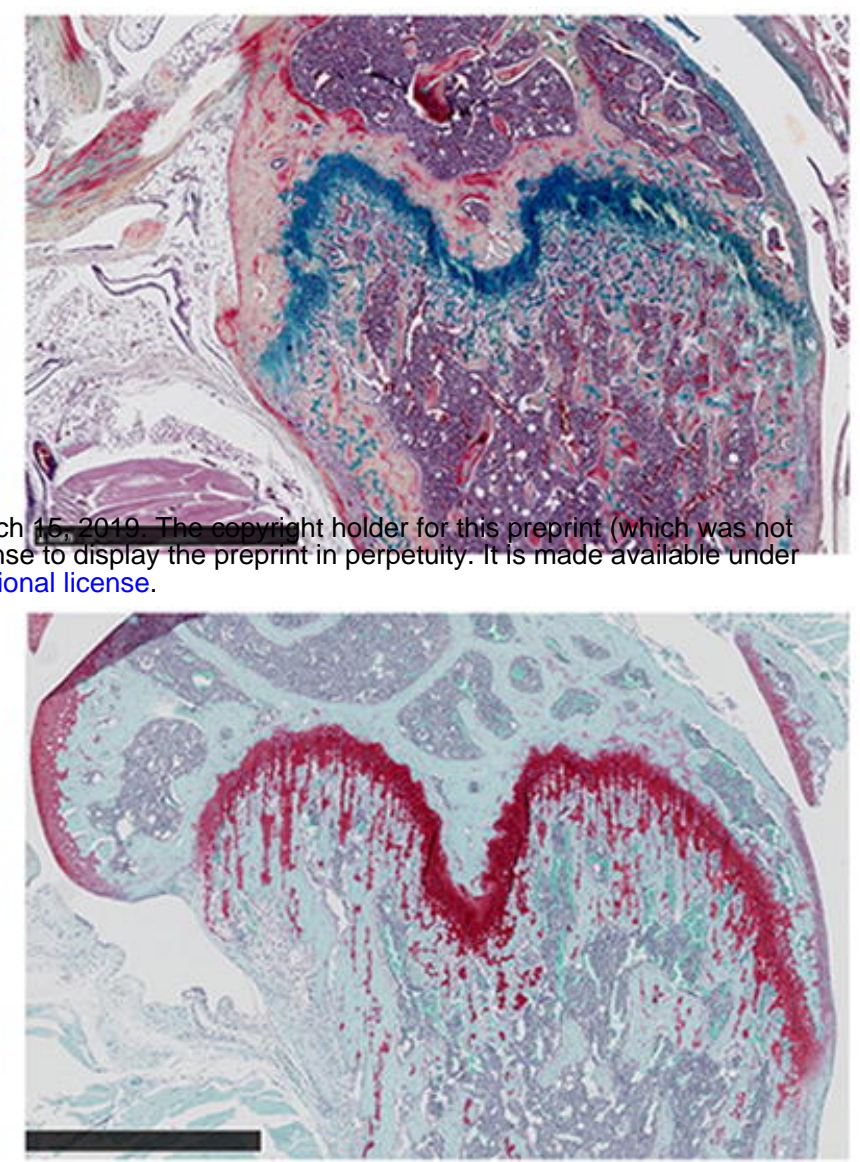

\section{K3KI}
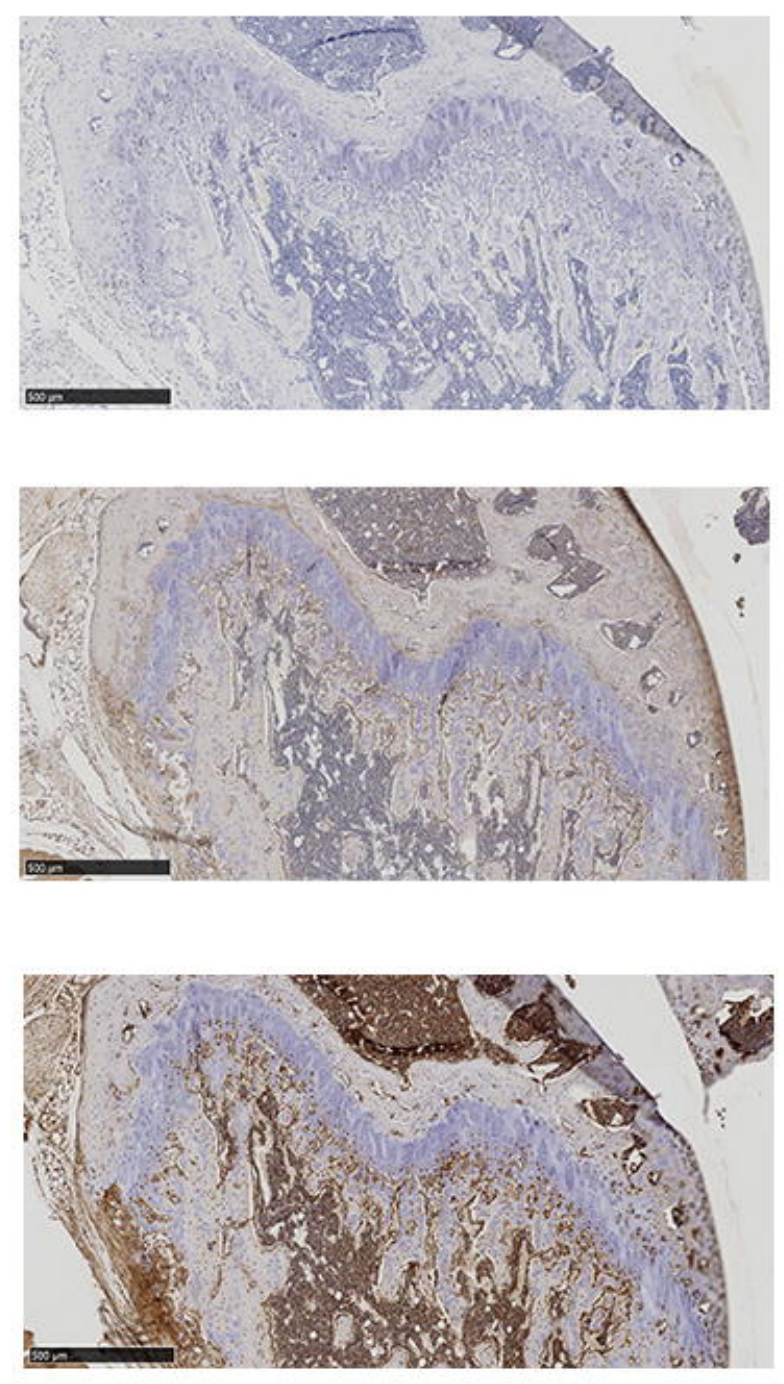

sox 9

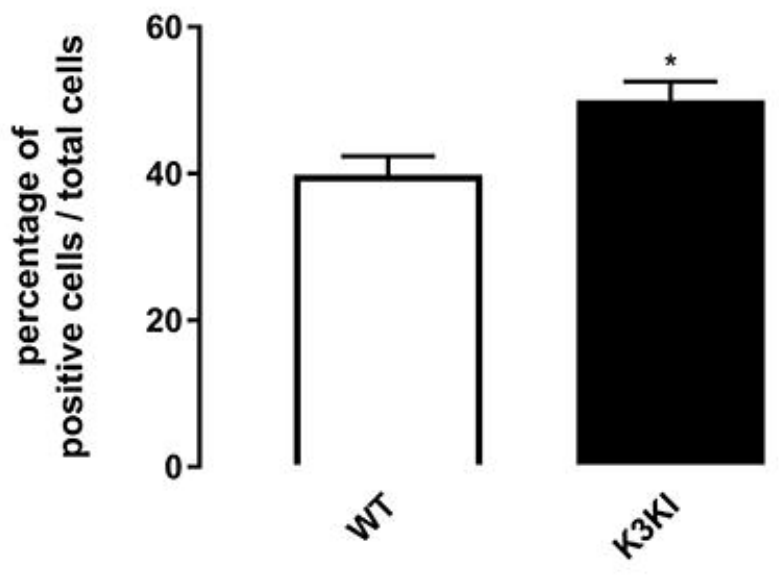

Collagen II

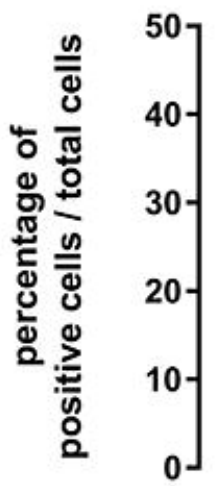

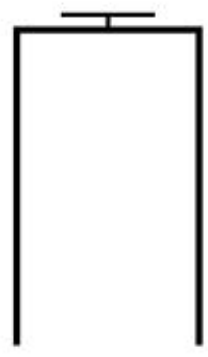

s

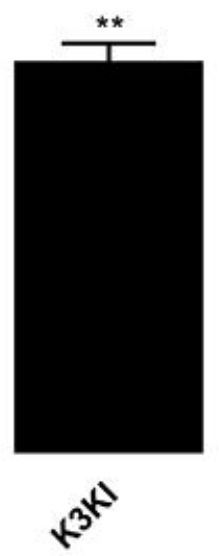

Collagen X
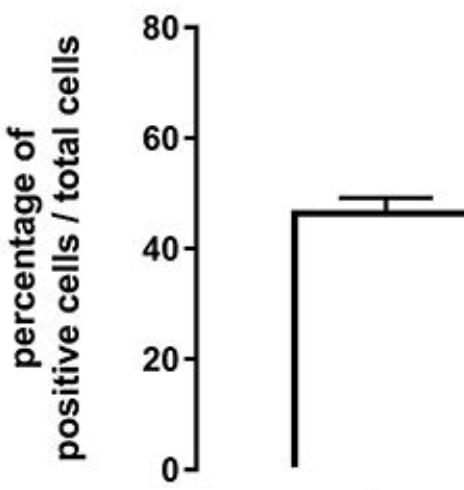

s

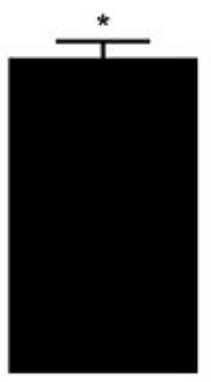

$x^{35}$ 


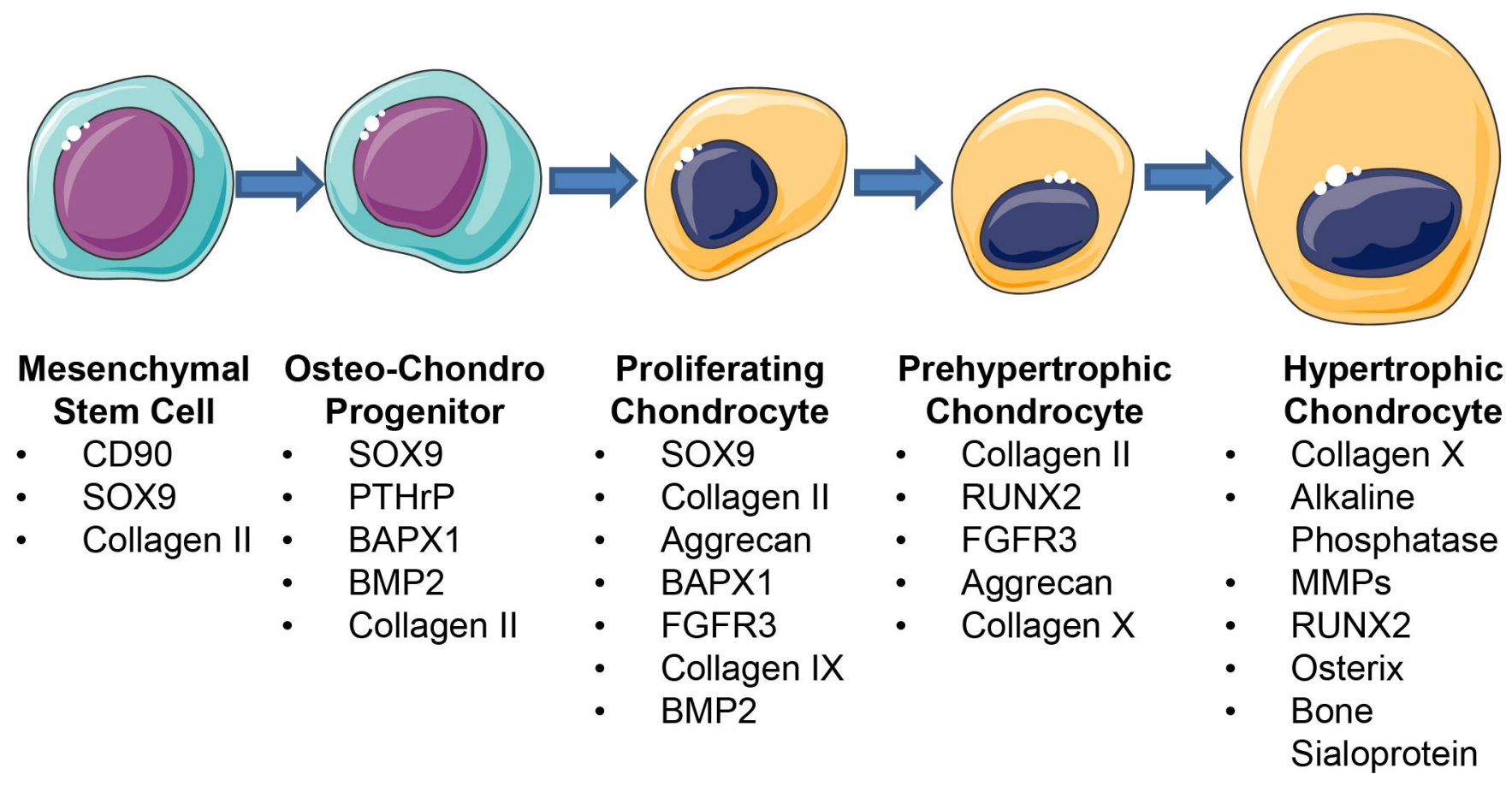

\section{SoX9}

RUNX2

Kindlin-3 